Atmos. Chem. Phys., 13, 10303-10324, 2013

www.atmos-chem-phys.net/13/10303/2013/

doi:10.5194/acp-13-10303-2013

(c) Author(s) 2013. CC Attribution 3.0 License.

\title{
Modeling polarized solar radiation from the ocean-atmosphere system for CLARREO inter-calibration applications
}

\author{
W. Sun ${ }^{1}$ and C. Lukashin ${ }^{2}$ \\ ${ }^{1}$ Science Systems and Applications Inc., Hampton, VA, 23666, USA \\ ${ }^{2}$ NASA Langley Research Center, Hampton, VA, 23681, USA
}

Correspondence to: W. Sun (wenbo.sun-1@nasa.gov)

Received: 5 June 2013 - Published in Atmos. Chem. Phys. Discuss.: 4 July 2013

Revised: 30 August 2013 - Accepted: 11 September 2013 - Published: 23 October 2013

\begin{abstract}
Reflected solar radiance from the Earthatmosphere system is polarized. Radiance measurements can be affected by light's state of polarization if the radiometric sensor has polarization dependence. To enable the Climate Absolute Radiance and Refractivity Observatory (CLARREO) mission for inter-calibration of the imagers with polarization dependence, such as the MODIS, the polarization state of the light must be known with sufficient accuracy. For this purpose, the polarized solar radiation from the ocean-atmosphere system is studied with an adding-doubling radiative transfer model (ADRTM). The Cox-Munk ocean wave slope distribution model is used in calculation of the reflection matrix of a wind-ruffled ocean surface. An empirical foam spectral reflectance model and an empirical spectral reflectance model for water volume below the surface are integrated in the ocean-surface model. Solar reflectance from the ADRTM is compared with that from the discrete-ordinate radiative transfer (DISORT) model. Sensitivity studies are conducted for various ocean-surface and atmospheric conditions for the stratification of polarization distribution models (PDMs), which are to be used in the inter-calibration of the polarization-sensitive imager measurements with the CLARREO data. This report presents the first accurate approach for making the spectral PDMs over broad solar spectra, which cannot be achieved by empirical PDMs based on the data from polarimetric sensors.
\end{abstract}

\section{Introduction}

Reflected solar radiance from the Earth-atmosphere system can be significantly polarized by the Earth's surface and by atmospheric components such as air molecules and aerosols.
Radiance measurements can be seriously affected by the state of polarization of the observed light if the radiometric sensor is sensitive to polarization. To use the highly accurate data from the Climate Absolute Radiance and Refractivity Observatory (CLARREO) mission (Wielicki et al., 2013; currently available online at http://journals.ametsoc.org/doi/ pdf/10.1175/BAMS-D-12-00149.1) to calibrate the solar imagers like MODIS (King et al., 1992) or its follow-on instrument VIIRS and geostationary imagers, the polarization state of the reflected solar light must be known with sufficient accuracy, e.g., better than $15 \%$ in root mean square (rms). Empirical polarization distribution models (PDMs) (Nadal and Breon, 1999; Maignan et al., 2009) based on the PARASOL data (Deschamps et al., 1994) can be used to correct radiometric bias in an imager's measurements (Lukashin et al., 2013). However, the incidence and viewing geometries of pertinent scene types of these empirical PDMs are limited by the specific sensors and their satellites' orbits and Equator-crossing times, etc., which may not always be applicable to other imagers on different satellites. For example, currently PARASOL is the only polarimetric sensor in orbit that is suitable for empirical PDM development. However, since PARASOL is in the A-train Sun-synchronous orbit and its CCD array has no cross-track scan function, its solar zenith angle (SZA) and viewing angles are limited. Although this may not be a problem for VIIRS since it is also in the A-train Sun-synchronous orbit with an Equator-crossing time of 13:30 LT, for imagers not in the A-train orbit, such as the geostationary ones, the empirical PDMs based on the PARASOL polarimetric data will be insufficient to cover all viewing and solar geometries. Also, CLARREO is designed to measure solar spectra, with spectral coverage from 320 to 


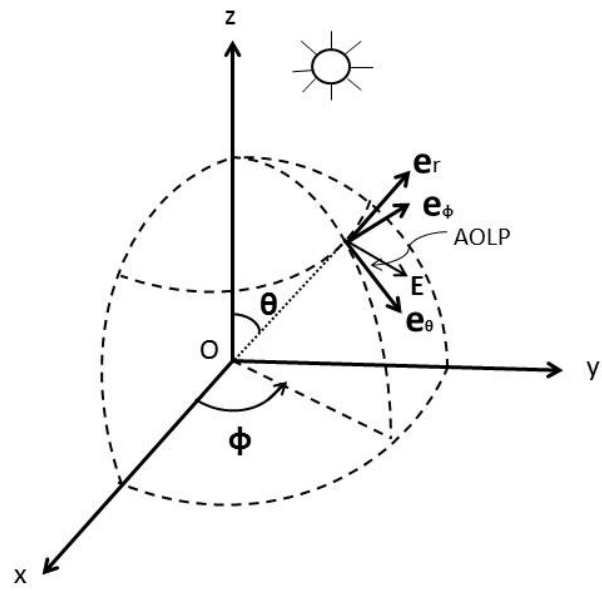

Fig. 1. Geometry of light's reflection in the ocean-atmosphere system.

$2300 \mathrm{~nm}$ and spectral sampling of $4 \mathrm{~nm}$, which has potential to inter-calibrate spaceborne sensors at nearly all of the solar wavelengths. Thus, the PDMs for the inter-calibration applications should be made over the broad solar spectra, and this cannot be achieved by using the available polarimetric measurements from PARASOL at only 3 wavelengths (i.e., 490, 670, and $865 \mathrm{~nm}$ ). Furthermore, polarization sensitivity studies are necessary in stratification of the PDMs for different surface scene types and atmospheric conditions, as well as incidence and viewing geometries, etc. These polarization sensitivity studies require comprehensive modeling of the polarized solar radiation's sensitivity to the surface and atmospheric optical properties in order to optimize stratification of the PDMs. Therefore, numerical modeling of the polarized solar radiation from the Earth-atmosphere system is critical for making accurate and efficient PDMs.

Sensitivity to polarization of imaging radiometers such as MODIS and VIIRS is obtained during instrument characterization before launch, and expressed in polarization factor. These factors are corrections of the baseline (unpolarized) gain, and depend on the instrument band, scan angle, and angle of polarization (Sun and Xiong, 2007). Taking into account this framework, the PDM should be developed in a consistent manner, providing information on the degree of polarization (DOP), and the angle of linear polarization (AOLP) of the reflected solar radiation at the top of the atmosphere (TOA). As demonstrated in a previous study by Lukashin et al. (2013), the DOP strongly depends on the scene type (clear sky and clouds, etc.), and both DOP and AOLP strongly depend on solar and viewing geometry. Modeling the polarization of the reflected light from the Earthatmosphere system must comprehensively consider all these issues, as well as detailed physics in radiative transfer. Before describing our approach to numerical modeling of the PDMs, we would like to briefly review the fundamentals relevant to polarization of reflected light.
Following Mischenko and Travis (1997), we set a righthanded Cartesian coordinate system as shown in Fig. 1, with the $z$ axis directed vertically to the upper boundary of the atmosphere and $x o z$ being the principal plane. The Sun is in the principal plane and over the negative $x$ axis of the coordinate system in this figure. The direction of the reflected light from the ocean-atmosphere system is specified by the unit vector $\boldsymbol{e}_{\mathrm{r}}$, and $\theta$ and $\phi$ denote the viewing zenith angle (VZA) and relative azimuth angle (RAZ), respectively. In the local right-handed orthonormal coordinate system formed by the unit vectors $\boldsymbol{e}_{\mathrm{r}}, \boldsymbol{e}_{\theta}$, and $\boldsymbol{e}_{\phi}$, we have $\boldsymbol{e}_{\mathrm{r}}=\boldsymbol{e}_{\boldsymbol{\theta}} \times \boldsymbol{e}_{\phi}$, where $\boldsymbol{e}_{\theta}$ lies in the meridian plane of the reflected light beam. The AOLP of the reflected radiance in the direction of $\boldsymbol{e}_{\mathrm{r}}$ is the angle between the local meridian line and the electric vector of the linearly polarized light, counted counterclockwise when viewing in the reverse direction of the reflected radiance. Also, in the local right-handed orthonormal coordinate system formed by the unit vectors $\boldsymbol{e}_{\mathrm{r}}, \boldsymbol{e}_{\theta}$, and $\boldsymbol{e}_{\phi}$, the common intensity and the polarization state of any quasi-monochromatic light can be completely specified by the Stokes parameters $I, Q, U$, and $V$. Following the definition in Hansen and Travis (1974), we have

$$
\begin{gathered}
I=<E_{\theta} E_{\theta}^{*}+E_{\phi} E_{\phi}^{*}>, \\
Q=<E_{\theta} E_{\theta}^{*}-E_{\phi} E_{\phi}^{*}>, \\
U=<E_{\theta} E_{\phi}^{*}+E_{\phi} E_{\theta}^{*}>, \\
V=i<E_{\phi} E_{\theta}^{*}-E_{\theta} E_{\phi}^{*}>,
\end{gathered}
$$

where $E_{\theta}$ and $E_{\phi}$ are the $\theta$ and $\phi$ components of the electric field in the local right-handed orthonormal coordinate system, respectively. The asterisk denotes the complexconjugate value, and angular brackets denote averaging in time. It is well known that any arbitrarily polarized incoherent radiation denoted by Stokes parameters $I, Q, U$, and $V$ can be represented by a sum of an unpolarized part and a $100 \%$ polarized part as

$$
\left[\begin{array}{c}
I \\
Q \\
U \\
V
\end{array}\right]=\left[\begin{array}{c}
I-\sqrt{Q^{2}+U^{2}+V^{2}} \\
0 \\
0 \\
0
\end{array}\right]+\left[\begin{array}{c}
\sqrt{Q^{2}+U^{2}+V^{2}} \\
Q \\
U \\
V
\end{array}\right] .
$$

For a sensor with polarization dependence, the measurement of the polarized portion of light $\left[\sqrt{Q^{2}+U^{2}+V^{2}}, Q\right.$, $U, V]$ is a function of the polarization angle. As an extreme example, a linearly polarized lens can transmit a linearly polarized light $\left[\sqrt{Q^{2}+U^{2}}, Q, U, 0\right]$ from 0 to $100 \%$, depending on the AOLP relative to the polarization direction of the lens. 
Since the circularly polarized radiance from the oceanatmosphere system is negligible $(V \approx 0)$ (Coulson, 1988), only the total radiance $I$ and linearly polarized radiance $Q$ and $U$ need to be calculated in this study. Without considering the circularly polarized radiance $(V \approx 0)$ at TOA, the DOP and AOLP are defined in terms of Stokes parameters, respectively, as

$\mathrm{DOP}=\frac{\sqrt{Q^{2}+U^{2}}}{I}$

and

$\mathrm{AOLP}=\frac{1}{2} \tan ^{-1}\left(\frac{U}{Q}\right)+\alpha_{0}$,

where $\alpha_{0}=0^{\circ}$ if $Q>0$ and $U \geq 0 ; \alpha_{0}=180^{\circ}$ if $Q>0$ and $U<0 ; \alpha_{0}=90^{\circ}$ if $Q \leq 0$. The physical meaning of AOLP is illustrated in Fig. 1. When both DOP and AOLP of the radiance are known, the sensor-measured intensity counts of light can be expressed as

$C_{\mathrm{m}}=G_{0} \cdot(1-D O P) \cdot I+G_{\mathrm{p}}(\mathrm{AOLP}) \cdot \mathrm{DOP} \cdot I$,

where $I$ denotes the actual intensity of the light to be measured, $G_{0}$ and $G_{\mathrm{p}}$ (AOLP) are sensor's gain factors for unpolarized radiation and linearly polarized radiation, respectively. $G_{\mathrm{p}}(\mathrm{AOLP})$ is the ratio of the sensor-measured intensity count to the intensity of the linearly polarized incidence light source used for calibrating the instrument, and $G_{0}$ can be derived as a mean value of $G_{\mathrm{p}}$ (AOLP) over all AOLPs. From Eq. (5), the actual radiance can be derived from the measured value as

$I=\frac{C_{\mathrm{m}} / G_{0}}{1+\left[\frac{G_{\mathrm{p}}(\mathrm{AOLP})-G_{0}}{G_{0}}\right] \cdot \mathrm{DOP}}$,

where $C_{\mathrm{m}} / G_{0}$ is simply the measured intensity without polarization correction, and $\left[\frac{G_{\mathrm{p}}(\mathrm{AOLP})-G_{0}}{G_{0}}\right]$, as a function of AOLP, is the imager's sensitivity-to-polarization factor, obtained during the prelaunch calibration of the instrument. Note here that for a well-depolarized imager, $m($ AOLP $)=$ $\left[\frac{G_{\mathrm{p}}(\mathrm{AOLP})-G_{0}}{G_{0}}\right]$ should be a quantity with $|m(\mathrm{AOLP})|<<1$. Therefore, using $\frac{1}{1+x} \approx 1-x$ for small $x$, Eq. (6) can be expressed as

$I \approx\left(C_{\mathrm{m}} / G_{0}\right) \cdot[1-m(\mathrm{AOLP}) \cdot \mathrm{DOP}]$.

The relative error (RE) of the measured intensity due to polarization can then be calculated as

$\mathrm{RE}=\frac{\left(C_{\mathrm{m}} / G_{0}\right)-I}{I} \approx \frac{m(\mathrm{AOLP}) \cdot \mathrm{DOP}}{1-m(\mathrm{AOLP}) \cdot \mathrm{DOP}} \approx m(\mathrm{AOLP}) \cdot \mathrm{DOP}$.

In deriving Eq. (8), we neglected the second-order small value $[m(\mathrm{AOLP}) \times \mathrm{DOP}]^{2}$. Thus, e.g., for a sensor with a sensitivity-to-polarization factor of only $1 \%$, its measurement for light with a DOP of $30 \%$ will have relative error of $0.3 \%$ solely due to the polarization.
Equation (6) gives the way of using the DOP and AOLP in correction of measured radiance errors caused by the polarization of the reflected light and the polarization dependence of the radiation sensor. The polarization correction could be more complicated for an imager with scan mirror optical system (Sun and Xiong, 2007; Lukashin et al., 2013), when the sensor's gain factors $G_{0}$ and $G_{\mathrm{p}}$ (AOLP) are also the functions of scanning angle. In summary, Eq. (6) shows that if the DOP and AOLP of the reflected solar light at TOA are known, the correction of errors caused by the polarization of light in the ocean-atmosphere-reflected radiance measured by polarization-dependent remote sensors can be accurately done. In this study, we will couple an atmospheric radiative transfer model with a rough-ocean-surface light reflection matrix, to model the solar radiation through the oceanatmosphere system, focusing on the DOP and AOLP of the reflected solar light at TOA while addressing the total radiance of the reflected light.

\section{Atmospheric radiative transfer model}

A variety of techniques have been developed for computing the radiative transfer including multiple-scattering light through the atmosphere. The most frequently used algorithms that can calculate not only total radiance but also the polarization state of light include the invariant imbedding method (Ambartsumian, 1958; Adams and Kattawar, 1970; Hansen and Travis, 1974; Mishchenko and Travis, 1997), the method of successive-order scattering (van de Hulst, 1948; Dave, 1964; Irvine, 1965; Hovenier, 1971; Hansen and Travis, 1974; Min and Duan, 2004; Lenoble et al., 2007; Zhai et al., 2010; Duan et al., 2010), the Monte Carlo method (Hammersley and Handscomb, 1964; Plass and Kattawar, 1968; Kattawar et al., 1973; Hansen and Travis, 1974; Mayer, 2009; Cornet et al., 2010), the discrete ordinate method (Chandrasekhar, 1950; Hansen and Travis, 1974; Stamnes et al., 1988; Schulz et al., 1999; Rozanov and Kokhanovsky, 2006; Ota et al., 2010), and the adding-doubling method (Stokes, 1862; Peebles and Plesset, 1951; van de Hulst, 1963; Twomey et al., 1966; Hansen and Hovenier, 1971; Hansen and Travis, 1974; de Haan et al., 1987; Evans and Stephens, 1991). Some of these methods were already applied to the study of ocean-atmosphere system: e.g., the Monte Carlo method was applied to study the effect of ocean refractive index on the polarization of light over a calm ocean (Kattawar and Adams, 1989); the method of successive-order scattering was applied to study the water color of a planar ocean (Chami et al., 2001, 2007); and the adding-doubling method was used in the study of the polarized reflection from a wind-ruffled ocean (Takashima and Masuda, 1985), the study of the polarized light at the $\mathrm{O}_{2}$ A band from a Lambertian ocean (Stam et al., 1999), and in the study of ocean polarized reflectance including water-leaving radiation for precise aerosol retrieval (Chowdhary et al., 2005, 2006). In this study, we employ the 
adding-doubling method, and couple it with a rough-oceansurface light reflection matrix, to model the reflected solar radiation from the ocean-atmosphere system, focusing on deriving the DOP and AOLP of the reflected light at TOA, for using these parameters in correcting measurements from polarization-sensitive instruments in orbit.

In the adding-doubling algorithm, the medium in which the light propagates is separated into many optically thin sublayers. The optical thickness of each sublayer is set to be so small that the optical properties of the sublayer can be represented simply by single-scattering ones. If reflection and transmission are known for each of the two adjacent sublayers, the reflection and transmission from the combined layer can be obtained by computing the successive reflections back and forth between the two sublayers. If the optical properties of the two sublayers are identical, the results for the combined layer can be built up rapidly in a doubling manner. In the practice of adding-doubling programming, Fourier decomposition is made for the Stokes vector and also for the scattering phase matrix. The numerical solution is obtained for each Fourier component, and the Stokes vector of the transferred light is calculated with these Fourier components (de Haan et al., 1987; Evans and Stephens, 1991). Due to its simple essence, the adding-doubling method is a standard radiative transfer algorithm that has a long history of applications and documentations and does not need to be further introduced here. In this study, the adding-doubling model follows the latest program development in this method (Hansen and Travis, 1974; Evans and Stephens, 1991), which can be applied to calculate all Stokes parameters of the radiation through a plane-parallel atmosphere composed of absorbing gas, scattering molecules, scattering particulates including various aerosols, water cloud droplets, and ice cloud particles.

In this study, the atmosphere is assumed to be planeparallel and separated into 32 layers with the ocean surface as the reflecting boundary layer. The atmospheric profiles, which give the pressure, temperature, water vapor, and ozone as functions of altitude, are from the tables of tropical (TPC), midlatitude summer (MLS), midlatitude winter (MLW), sub-Arctic summer (SAS), and sub-Arctic winter (SAW) atmospheric profiles (McClatchey et al., 1972). The US standard (STD) atmosphere (1976) is also applied in sensitivity studies in this report. We use gas absorption coefficients from the $k$-distribution treatment (Kato et al., 1999) of the spectral data from the line-by-line radiative transfer model (LBLRTM) (Clough et al., 1992; 1995) using the MODTRAN 3 dataset (Kneizys et al., 1988). Ozone absorption coefficients are also taken from the ozone crosssection table provided by the World Meteorological Organization (1985) for wavelengths smaller than $700 \mathrm{~nm}$. Molecular scattering optical thickness above any pressure level, $P$, is from (Hansen and Travis, 1974)

$$
\tau=0.008569 \lambda^{-4}\left(1+0.0113 \lambda^{-2}+0.00013 \lambda^{-4}\right)\left(\frac{P}{P_{0}}\right),
$$

where $\lambda$ is the wavelength of light in $\mu \mathrm{m}, P$ is the pressure in $\mathrm{mb}$, and $P_{0}=1013.25 \mathrm{mb}$ is the standard surface pressure. The scattering phase matrix elements of molecular atmosphere are based on Rayleigh scattering solution with a depolarization factor of 0.03 (Hansen and Travis, 1974). Single-scattering properties of aerosol and cloud particles are calculated differently: for spherical droplets including liquid aerosols and water cloud particles, Mie solution (Mie, 1908; Fu and Sun, 2001) is applied; for solid- or mixed-phase aerosols or small ice crystals, which are usually nonspherical particles, the finite-difference time domain (FDTD) light scattering model (Sun et al., 1999, 2002, 2013), the scatteredfield pseudo-spectral time domain (PSTD) light scattering model (Sun et al., 2013), and the discrete dipole approximation (DDA) light scattering model (Zubko et al., 2006, 2009) will be used; for large ice crystals, we will use the data from geometric optics approximation (GOA) (Macke, 1993; Yang and Liou, 1996). The C1 size distribution (Deirmendjian, 1969) is used for water cloud droplets. The 28 measured ice-crystal size distributions used in Fu (1996) and the two other size distributions in Mitchell et al. (1996) will be used to calculate the volume single-scattering properties of ice clouds. Two-mode lognormal size distributions (Davies, 1974; Whitby, 1978; Reist, 1984; Ott, 1990; Porter and Clarke, 1997) are applied for aerosols.

Traditional radiative transfer models generally assume independent radiation process for molecules and aerosol or cloud particles, which means that molecular radiation process and particulate process are assumed at different layers of atmosphere to avoid the convolution of the light scattering phase functions of molecules and particulates in the radiative transfer calculations. This may involve errors due to unphysical single-scattering properties in each layer. In this study, for layers with more than one type of scattering atmospheric components, such as layers with both air molecules and aerosols, and layers composed of air molecules, aerosols, and cloud particles, the mixed single-scattering properties, including absorption and scattering coefficients and phase matrix elements, are calculated, as the mixed optical property of the layer. In calculation of the mixed values, singlescattering properties of individual agents are weighted by their optical thickness.

In the radiative transfer calculations, the phase matrix elements of particulate atmospheric components are input to the radiative transfer model as Legendre polynomial series (e.g., Evans and Stephens, 1991). If the phase matrix elements of the scattering particles have strong forward-scattering peaks (what happens on large cloud particles), it needs many Legendre high-order terms to approach the original phase matrix elements, which will heavily increase the computation time and memory of the radiative transfer calculation due to the large increment in the Legendre terms and stream number 


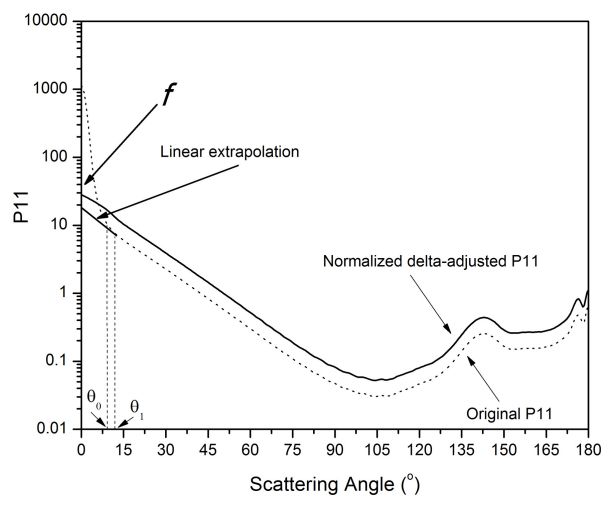

Fig. 2. Illustration of delta adjustment on phase function.

in the modeling. To avoid this problem, we conduct a delta adjustment (e.g., Hansen, 1968) to the layer's mixed singlescattering properties prior to the Legendre series expansion of the scattering phase matrix elements. This means a truncation of the forward-scattering peak in the phase matrix elements for particulate atmospheric components. In this study, this is done in a way as shown in Fig. 2, exemplified by the conventional phase function $\left(P_{11}\right)$ of a water cloud. The scattering peak between the scattering angle of $\theta_{0}$ and the forward-scattering direction is truncated and replaced by values from a linear extrapolation algorithm

$$
\frac{\log _{10} P_{11}(\theta)-\log _{10} P_{11}\left(\theta_{1}\right)}{\left(\theta-\theta_{1}\right)}=\frac{\log _{10} P_{11}\left(\theta_{0}\right)-\log _{10} P_{11}\left(\theta_{1}\right)}{\left(\theta_{0}-\theta_{1}\right)},
$$

where $\theta_{0}$ and $\theta_{1}$ are two neighboring scattering angles and $\theta_{1}>\theta_{0}$, and $\theta$ is any scattering angle between 0 and $\theta_{0}$. The truncated phase function is integrated over the scattering angle to obtain the energy loss fraction $f$ due to the truncation of the forward-scattering peak, which is the difference between the integral of original phase function and the integral of truncated phase function over scattering angles. After the energy loss fraction $f$ is obtained, the scattering optical thickness $\left(\tau_{\mathrm{s}}^{\prime}\right)$, total optical thickness $\left(\tau^{\prime}\right)$, and singlescattering albedo $\left(\alpha^{\prime}\right)$ of the adjusted cloud are

$\tau_{\mathrm{s}}^{\prime}=(1-f) \tau_{\mathrm{s}}$,

$\tau^{\prime}=\tau_{\mathrm{a}}+\tau_{\mathrm{s}}^{\prime}$,

and

$\alpha^{\prime}=\tau_{\mathrm{s}}^{\prime} / \tau^{\prime}$,

where $\tau_{\mathrm{s}}$ and $\tau_{\mathrm{a}}$ are the scattering and absorption optical thickness of the original clouds, respectively. Other elements of phase matrix are also adjusted by conserving their ratio values to the conventional phase function $\left(P_{11}\right)$ (e.g., $P_{12} / P_{11}$ does not change after the adjustment). The adjusted phase matrix elements are renormalized by $(1-f)$.
The delta-adjustment treatment may cause some numerical errors in calculation of the total reflectance from the clouds due to the strong forward-scattering peak in their phase-matrix elements. However, since radiation from clouds has a very low degree of polarization, which we show later, the delta-adjustment approximation should not cause any significant errors in the correction of radiance measurement caused by polarization state of light in remote-sensing intercalibration applications.

\section{Surface reflection model}

The major expansion to the adding-doubling method in this study is the coupling of the rough-ocean-surface light reflection matrix with the atmospheric layers. The ocean-surface light reflection matrix is obtained based on an empirical foam spectral reflectance model (Koepke, 1984), an empirical spectral reflectance model for water volume below the surface (Morel, 1988), and the standard Kirchhoff approach under the stationary phase approximation (Mishchenko and Travis, 1997) for foam-free waves with slope distribution as given in Cox and Munk $(1954,1956)$. To examine the dependence of the reflected light's polarization on the direction of wind over ocean, the wave slope distribution models with the Gram-Charlier series expansion (Cox and Munk, 1954), and without the Gram-Charlier series expansion (Cox and Munk, 1956), are both integrated in the adding-doubling radiative transfer model. The surface reflection matrix with $4 \times 4$ elements is calculated as

$\mathbf{R}_{0}\left(\theta_{\mathrm{s}}, \theta_{\mathrm{v}}, \phi\right)=f \mathbf{R}_{\mathrm{WC}}+(1-f) \mathbf{R}_{\mathrm{WL}}+(1-f) \frac{\pi \mathbf{M}\left(\theta_{\mathrm{s}}, \theta_{\mathrm{v}}, \phi\right)}{4 \cos ^{4} \beta \cos \theta_{\mathrm{s}} \cos \theta_{\mathrm{v}}} P\left(Z_{x}, Z_{y}\right)$,

where $\theta_{\mathrm{s}}, \theta_{\mathrm{v}}$, and $\phi$ denote solar zenith angle, viewing zenith angle, and relative azimuth angle of the reflected light, respectively. The fraction of whitecap (WC) is denoted as $f$. The fraction of whitecaps has a large uncertainty, which not only depends on the wind speed but also on the fetch and on the factors altering the mean lifetime of the whitecaps, such as water temperature and thermal stability of the lower atmosphere (Koepke, 1984). In this study, we use the expression by Monahan and O'Muircheartaigh (1980)

$f=2.95 \times 10^{-6} W^{3.52}$,

where the wind speed $W$ is in the units of $\mathrm{m} \mathrm{s}^{-1}$. In Eq. (14), $\mathbf{R}_{\mathrm{WC}}$ is the whitecap reflection matrix. Since foam is generally assumed to be a Lambertian reflector, the only nonzero element of $\mathbf{R}_{\mathrm{WC}}$ is the reflectance, which is from an empirical foam spectral reflectance model (Koepke, 1984) in this study. The water-leaving (WL) reflection is also assumed to be Lambertian. Similar to $\mathbf{R}_{\mathrm{WC}}, \mathbf{R}_{\mathrm{WL}}$ has only one nonzero element, the reflectance of water volume below the surface, which is obtained from an empirical spectral reflectance model (Morel, 1988) with an ocean water pigment concentration of $0.01 \mathrm{mg} \mathrm{m}^{-3}$. The $4 \times 4$ elements of $\boldsymbol{M}\left(\theta_{\mathrm{s}}, \theta_{\mathrm{v}}, \phi\right)$ for 
each wave facet orientation are calculated in the same way as in Mishchenko and Travis (1997) based on the Fresnel Laws. As given in Cox and Munk (1954, 1956), $P\left(Z_{x}, Z_{y}\right)$ is the wave slope probability distribution as a function of the two components of the surface slope

$Z_{x}=\frac{\partial Z}{\partial x}=\frac{\sin \theta_{\mathrm{v}} \cos \phi-\sin \theta_{\mathrm{s}}}{\cos \theta_{\mathrm{v}}+\cos \theta_{\mathrm{s}}}$

and

$Z_{y}=\frac{\partial Z}{\partial y}=\frac{\sin \theta_{\mathrm{v}} \sin \phi}{\cos \theta_{\mathrm{v}}+\cos \theta_{\mathrm{s}}}$,

where $Z$ denotes the height of the surface. In Eq. (14), $\beta$ is the tilting angle of wave facet; thus

$\tan \beta=\sqrt{Z_{x}^{2}+Z_{y}^{2}}$.

If wind direction is not accounted for, Cox and Munk (1956) gives $P\left(Z_{x}, Z_{y}\right)$ as a function of wind speed in a form

$P\left(Z_{x}, Z_{y}\right)=\frac{1}{\pi \sigma^{2}} \exp \left(-\frac{Z_{x}^{2}+Z_{y}^{2}}{\sigma^{2}}\right)$

where $\sigma^{2}$ is linearly related to wind speed $W\left(\mathrm{~ms}^{-1}\right)$ in an empirical form

$\sigma^{2}=0.003+5.12 \times 10^{-3} W$.

Furthermore, to study the sensitivity of reflected light's polarization state to wind direction over the ocean, we also integrate in the model a form of the wave slope probability distribution with a Gram-Charlier series expansion (Cox and Munk, 1954)

$$
\begin{aligned}
& P\left(Z_{\mathrm{c}}, Z_{\mathrm{u}}\right)=\frac{1}{2 \pi \sigma_{\mathrm{c}} \sigma_{\mathrm{u}}} \exp \left(-\frac{\xi^{2}+\eta^{2}}{2}\right)\left[1-\frac{c_{21}}{2}\left(\xi^{2}-1\right) \eta-\frac{c_{03}}{6}\left(\eta^{3}-3 \eta\right)+,\right. \\
& \left.\frac{c_{40}}{24}\left(\xi^{4}-6 \xi^{4}+3\right)+\frac{c_{0}}{24}\left(\eta^{4}-6 \eta^{2}+3\right)+\frac{c_{22} 2}{4}\left(\xi^{2}-1\right)\left(\eta^{2}-1\right)+\cdots\right]
\end{aligned}
$$

where $\xi=\frac{Z_{\mathrm{c}}}{\sigma_{\mathrm{c}}}$ and $\eta=\frac{Z_{\mathrm{u}}}{\sigma_{\mathrm{u}}}$, with $Z_{\mathrm{c}}$ and $Z_{\mathrm{u}}$ denoting the two components of the surface slope crosswind and upwind, and $\sigma_{\mathrm{c}}$ and $\sigma_{\mathrm{u}}$ denoting the rms values of $Z_{\mathrm{c}}$ and $Z_{\mathrm{u}}$, respectively. $\sigma_{\mathrm{c}}^{2}, \sigma_{\mathrm{u}}^{2}$, and the coefficients $c_{21}, c_{03}, c_{40}, c_{04}$, and $c_{22}$ are all empirical linear functions of wind speed as given in Cox and Munk (1954). The geometry for the definition of wind direction is illustrated in Fig. 3.

The ocean surface is treated as the bottom (1st) layer in the adding-doubling calculation in this study. The cosine azimuth modes (coefficients) and sine azimuth modes from the Fourier transformation of the ocean reflection matrix elements are integrated into the adding-doubling process as the bottom layer optical properties functioning as boundary conditions. In this study, the $4 \times 4$ ocean reflection matrix elements calculated in Eq. (14) are transformed into cosine azimuth modes or sine azimuth modes by discrete Fourier transform (DFT) over azimuth angles with a numerical Gauss integration.
Z

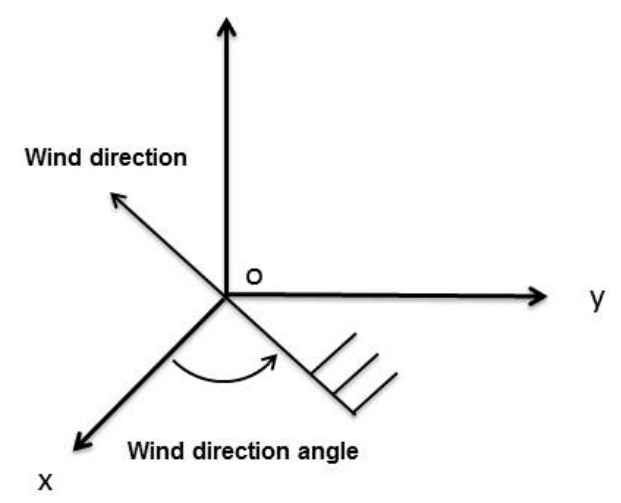

Fig. 3. Geometry of wind direction in the coordinate system.

\section{Numerical results}

The objective of this study is to enable and demonstrate numerical methods for building efficient PDMs to correct satellite-measured solar radiance, which has bias errors caused by the polarization of reflected light. The numerical results reported here will optimize the input parameters of the radiative transfer model for this purpose. The emphasis of our numerical calculation is to study the sensitivity of the polarization state of the reflected light to the parameters of solar wavelength, incidence and viewing geometries, surface conditions, and components of the atmosphere. This includes SZA, VZA, RAZ, reflection surface conditions, gas absorption, and molecular and particulate scattering to the light in the atmosphere. With these sensitivity studies, we aim to identify the incidence, surface, or atmospheric parameters to which the DOP and AOLP are not sensitive. These parameters are given certain values in the modeling and excluded from the input parameters for accessing PDM lookup tables. With this approach, we can make PDMs as functions of only necessary input parameters for quick accesses during polarization correction in practice.

In the ADRTM, the adding-doubling scheme is actually conducted on the modes (coefficients) of the Fourier series expansion of the Stokes parameters over azimuth angle (de Haan et al.,1987; Evans and Stephens, 1991). After the adding-doubling calculations, the cosine modes and sine modes (Evans and Stephens, 1991) of the Stokes parameters are transformed back into the Stokes parameters. Therefore, the number of the cosine modes and sine modes in the Fourier series expansion of the Stokes parameters affects the accuracy of the radiative transfer calculation. A bigger number is required for accurate calculation of radiation with stronger anisotropy. Sensitivity of modeled Stokes parameters to mode number shows that a mode number of 18 is adequate for modeling all atmospheric and ocean conditions.

Also, in adding-doubling schemes, the calculation for transferred light's sine and cosine modes of the Stokes 

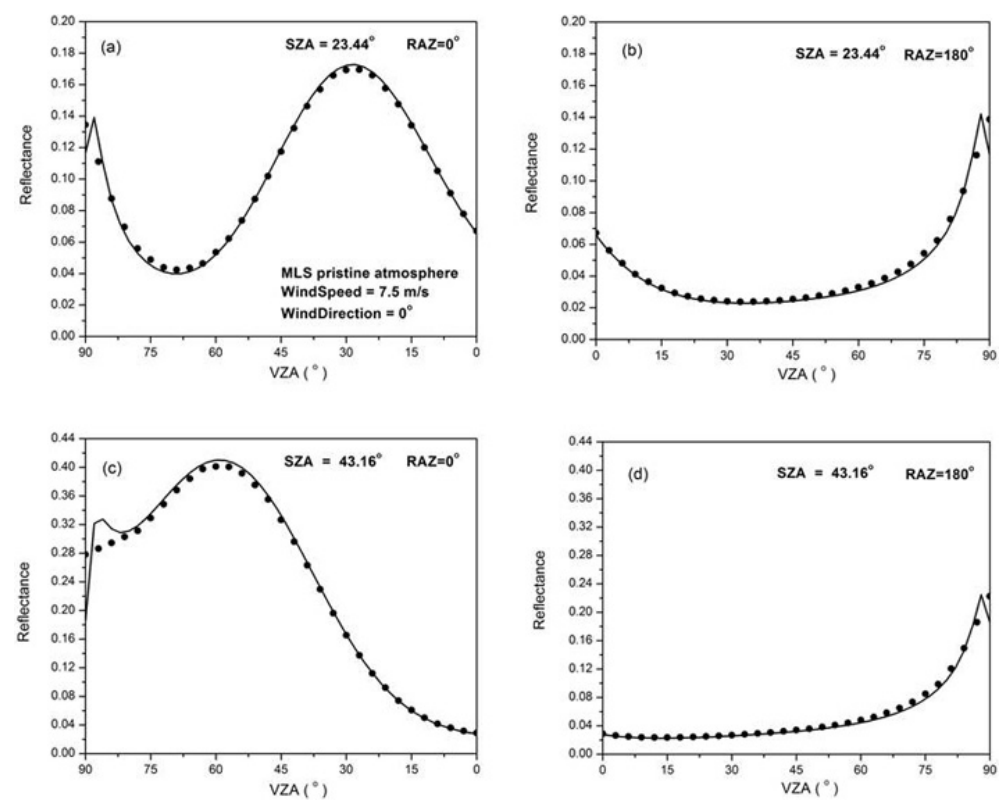

Fig. 4. Comparison of the total reflectance of the ocean-atmosphere system at a wavelength of $670 \mathrm{~nm}$ on the principal plane. Black dots and solid curves denote the results from the ADRTM and the DISORT, respectively. The atmosphere is of the midlatitude summer (MLS) atmosphere with only Rayleigh scattering and gas absorption. The wind speed is $7.5 \mathrm{~m} \mathrm{~s}^{-1}$ and wind direction is $0^{\circ}$. The solar zenith angle (SZA) for (a) and (b) is $23.44^{\circ}$ and for (c) and (d) is $43.16^{\circ}$. Thirty-six (36) streams are used in the DISORT and 18 streams and 18 Fourier expansion modes in the ADRTM.

parameters is conducted only on streams over discrete viewing zenith angles. Using more streams means higher resolution in the zenith angles and better accuracy in the results, but also means requiring more computational resources. To keep the computing time reasonable, we limited the number of streams to 18 . In this study, the streams follow a set of discrete Gaussian quadrature angles. Integration of radiance over limited discrete viewing zenith angles at Gaussian quadrature points can result in more accurate flux than over uniformly distributed discrete angles. However, this treatment will output Stokes parameters at Gaussian quadrature points, which is not the easiest way for storing and accessing the parameters during applications. To obtain the calculated Stokes parameters and the DOP and AOLP derived from these parameters over high-resolution uniform discrete viewing zenith angles, the Stokes parameters at only the Gaussian quadrature points are extrapolated and interpolated to the uniform grid points of viewing zenith angle. With this approach, using only 18 streams can produce accurate Stokes parameters of reflected light at all viewing angles and over nearly all atmospheric and ocean conditions.

Figure 4 shows the comparison of the total reflectance at the wavelength of $670 \mathrm{~nm}$ on the principal plane from the ADRTM and from the widely validated DISORT. The atmosphere is in the MLS pristine profile with only molecular scattering (Rayleigh scattering) and gas absorption. The empirical ocean foam and water-leaving reflectance models and the wave slope probability distribution model with a Gram-
Charlier series expansion (Cox and Munk, 1954), which is described in Sect. 3, are used. The wind speed is $7.5 \mathrm{~ms}^{-1}$ and wind direction is assumed in the reverse direction of $x$ axis as illustrated in Fig. 1 (i.e., wind direction is $0^{\circ}$ ). The solar zenith angle (SZA) is $23.44^{\circ}$ for Fig. $4 \mathrm{a}$ and $\mathrm{b}$, and $43.16^{\circ}$ for Fig. $4 \mathrm{c}$ and d. In the numerical simulations, we use 36 streams in the DISORT and 18 streams in the ADRTM. In the ADRTM calculation, the number of Fourier expansion modes is set to 18 . We can see that the total reflectance from the ADRTM is very close to that from the DISORT, with significant differences only at VZA $>\sim 80^{\circ}$, when the atmospheric path optical thickness is large. For VZA $<\sim 80^{\circ}$, the relative difference in reflectance from the ADRTM and the DISORT is smaller than $\sim 5 \%$. Since most in-orbit sensors do not report observations for VZA larger than $\sim 70^{\circ}$, the focus for the modeling quality is in the VZA range of 0 $70^{\circ}$. As a scalar approximation to a vector radiative transfer problem, DISORT has errors due to the negligence of polarization (Adams and Kattawar, 1970; Lacis et al., 1998). At small VZA, since the path optical thickness is small at the near-IR wavelength, the errors in the DISORT caused by the polarization of scattered light are also small, so the DISORT result is very close to the ADRTM data. At a larger SZA of $43.16^{\circ}$, the agreement of the DISORT and ADRTM results are even better. For VZA $<\sim 80^{\circ}$, the relative difference in reflectance from the ADRTM and the DISORT is smaller than $\sim 3 \%$. We also can see in the two cases that the total reflectance from DISORT is generally larger than that 

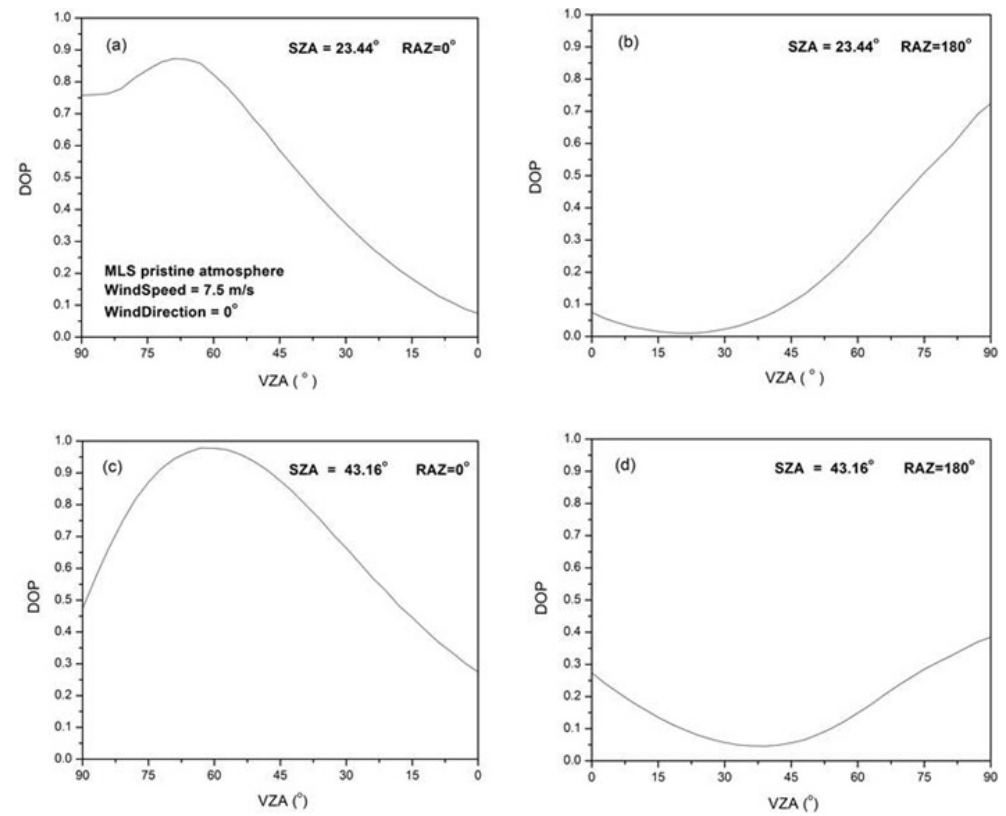

Fig. 5. Same as in Fig. 4, but for the DOP on the principal plane from the ADRTM. The solar zenith angle (SZA) for (a) and (b) is $23.44^{\circ}$ and for (c) and (d) is $43.16^{\circ}$.

of ADRTM in the forward-reflecting directions and smaller than that of ADRTM in the backward-reflecting directions. This is consistent with the results in Lacis et al. (1998). From these case studies, we can conclude that the ADRTM with 18 streams and 18 Fourier expansion modes can produce reflectance consistent with other radiative transfer models.

Figure 5 shows the DOP on the principal plane from the ADRTM for the cases in Fig. 4. We can see that for both of the solar incidence geometries, the DOPs reach their maxima at the VZA of $\sim 60^{\circ}$ in the forward-scattering direction and reach their minima at about the backscattering angles (i.e., $23.44^{\circ}$ and $43.16^{\circ}$, respectively). The DOPs also strongly depend on solar zenith angles. Larger solar zenith angles result in larger DOPs at nadir direction. Based on the definition of AOLP and the geometry illustrated in Fig. 1, the AOLPs for the cases in Fig. 5 as a function of VZA and RAZ over the RAZ range of $0-180^{\circ}$ are displayed in Fig. 6. We can see that on the principal plane, the AOLPs are $\sim 90^{\circ}$ at nearly all of the VZAs. Solar zenith angle significantly affects AOLP's distribution pattern in VZA and RAZ. Therefore, SZA, VZA, and RAZ are three critical parameters to determine DOP and AOLP in the PDMs.

To build a comprehensive set of PDMs, we also need to check the dependence of DOP and AOLP on the profiles of pristine atmosphere. Actually, the only significant effect of different pristine atmospheric profiles on reflected solar radiance spectra is the gas absorption to the light. Therefore, the sensitivity of solar light's polarization to pristine atmospheric profiles can be examined by studying the dependence of the DOP and AOLP on the gas absorption. Figure 7 shows the total reflectance, DOP, and AOLP at a water vapor absorption wavelength of $1200 \mathrm{~nm}$ at TOA, which is calculated with the ADRTM at a solar zenith angle of $43.16^{\circ}$ over a pristine clear-sky ocean with a wind speed of $7.5 \mathrm{~m} \mathrm{~s}^{-1}$. The total reflectance and DOP with the sub-Arctic winter atmosphere (solid curves) and those with the tropical atmosphere (black dots) are shown. Also shown are the AOLP with the sub-Arctic winter atmosphere (Fig. 7e) and those with the tropical atmosphere (Fig. 7f). Since the tropical atmosphere has much larger water vapor than the sub-Arctic winter atmosphere, the total reflectance at the water-vapor-absorption wavelength of $1200 \mathrm{~nm}$ from the tropical atmosphere is much smaller than that from the sub-Arctic atmosphere. However, we can see that DOP and AOLP are much less affected by the gas absorption in the atmosphere. This is consistent with the results for single scattering by particles (Sun et al., 2002). Therefore, gas absorption in different atmospheric profiles is important for total reflectance modeling, but has relatively insignificant effect on DOP and AOLP. A stratification of the atmospheric profiles into the TPC, MLS, MLW, SAS, and SAW atmosphere should be sufficient for accurate modeling of the DOP and AOLP of the reflected solar light over the globe.

It is well known that wind-caused ocean-surface roughness can significantly affect the total reflectance of solar light. However, it is not yet known how much wind speed and direction can affect the polarization state of reflected solar light at TOA. Figure 8 shows the total reflectance and DOP of the ocean-atmosphere system on the principal plane, which is calculated with the ADRTM at wavelength $670 \mathrm{~nm}$. Pristine 

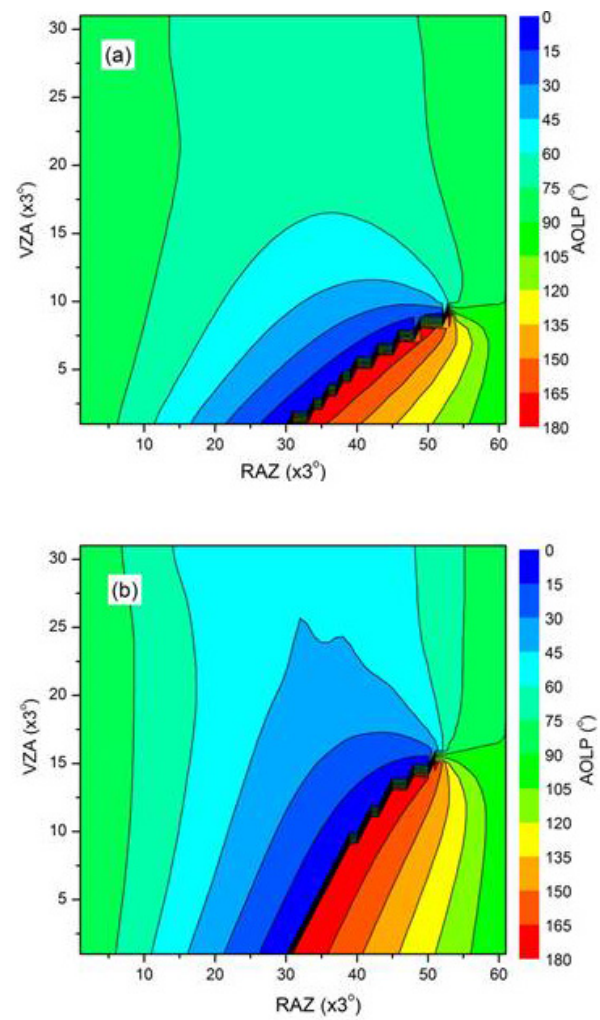

Fig. 6. Same as in Fig. 4, but for the AOLP from the ADRTM. The solar zenith angle (SZA) for (a) is $23.44^{\circ}$ and for (b) is $43.16^{\circ}$.

clear atmosphere with the US STD atmospheric profile is assumed. The SZA is $33.30^{\circ}$. Wind direction is assumed to be at $0^{\circ}$. Wind speeds are given as $5.0,7.5,10.0$, and $15.0 \mathrm{~m} \mathrm{~s}^{-1}$, respectively. We can see that wind speed significantly affects the total reflectance at $\mathrm{RAZ}=0^{\circ}$, but has only a small effect on the total reflectance at $\mathrm{RAZ}=180^{\circ}$. Wind speed effect on the DOP is also insignificant. The AOLPs of these cases are shown in Fig. 9. We should note that the AOLP values of $\sim 0^{\circ}$ and $\sim 180^{\circ}$ mean the same polarization plane of the linear polarization and have no difference to the measurement instrument. Thus the deep blue and deep red angular regions in Fig. 9 actually represent similar AOLPs and the same polarization direction. From Fig. 9, we can see that the wind speed effect on the AOLP is insignificant. In the PDM development and applications we will be able to use wind speed assimilated from GMAO weather data products. Our modeling results show that the uncertainty of wind speed data will only have a small impact on the DOP and AOLP.

Wind direction and ocean wave slope probability distribution models, like the one with wind-direction dependence (Cox and Munk, 1954) and the one without wind-direction dependence (Cox and Munk, 1956), could also affect the calculated reflectance and polarization state of the reflected light at TOA. Figure 10 shows the total reflectance and DOP on the principal plane, which is calculated with the ADRTM at wavelength $670 \mathrm{~nm}$. Pristine clear atmosphere with the US STD atmospheric profile is used. The SZA is $33.30^{\circ}$. Wind speed is $7.5 \mathrm{~m} \mathrm{~s}^{-1}$. Both the ocean wave slope probability distribution model with wind-direction dependence (Cox and Munk, 1954) and the one without wind-direction dependence (Cox and Munk, 1956) are used in the calculation. In the ocean wave slope probability distribution model with winddirection dependence, wind direction is set at 0,90 , and $180^{\circ}$, respectively. We can see that varying wind direction or using different ocean wave slope probability distribution models can significantly change the total reflectance at $R A Z=0^{\circ}$, but has little impact on the total reflectance at $\mathrm{RAZ}=180^{\circ}$. Varying wind direction, or using different ocean wave slope probability distribution models, has nearly no effect on the DOP at $R A Z=180^{\circ}$, and only causes small changes in the DOP at RAZ $=0^{\circ}$ when VZA $>60^{\circ}$. The AOLPs for the cases in Fig. 10 are shown in Fig. 11. The AOLPs from the ocean-surface models with different wind directions and different wave slope probability distributions show very similar patterns. Since wind direction may not be reliably obtained over ocean, and wind direction and wave slope distribution models have little effect on the polarization state of reflected light at TOA, we will use the Cox-Munk ocean wave slope probability distribution model without wind-direction dependence (Cox and Munk, 1956) in all of the following studies and in the future modeling for operational PDMs. Using the Cox-Munk ocean wave slope probability distribution model without wind-direction dependence can make the reflection field symmetric to the principal plane. Therefore, we only need to calculate and store the reflectance, DOP, and AOLP over the RAZ of $0-180^{\circ}$ in practice. These quantities will easily be obtained by symmetry for the RAZ of $180-360^{\circ}$. However, it is worth noting that among the Stokes parameters $I$ and $Q$ are symmetric to the principal plane, but $U$ and $V$ are oddly symmetric to the principal plane; i.e.,

$I\left(\mathrm{VZA}, 360^{\circ}-\mathrm{RAZ}\right)=I(\mathrm{VZA}, \mathrm{RAZ})$,

$Q\left(\mathrm{VZA}, 360^{\circ}-\mathrm{RAZ}\right)=Q(\mathrm{VZA}, \mathrm{RAZ})$,

$U\left(\mathrm{VZA}, 360^{\circ}-\mathrm{RAZ}\right)=-U(\mathrm{VZA}, \mathrm{RAZ})$,

$V\left(\mathrm{VZA}, 360^{\circ}-\mathrm{RAZ}\right)=-V(\mathrm{VZA}, \mathrm{RAZ})$.

From Eqs. (3), (4), and (22a-c), we can further derive out

$\mathrm{DOP}\left(\mathrm{VZA}, 360^{\circ}-\mathrm{RAZ}\right)=\mathrm{DOP}(\mathrm{VZA}, \mathrm{RAZ})$,

$\operatorname{AOLP}\left(\mathrm{VZA}, 360^{\circ}-\mathrm{RAZ}\right)=180^{\circ}-\mathrm{AOLP}(\mathrm{VZA}, \mathrm{RAZ})$. 

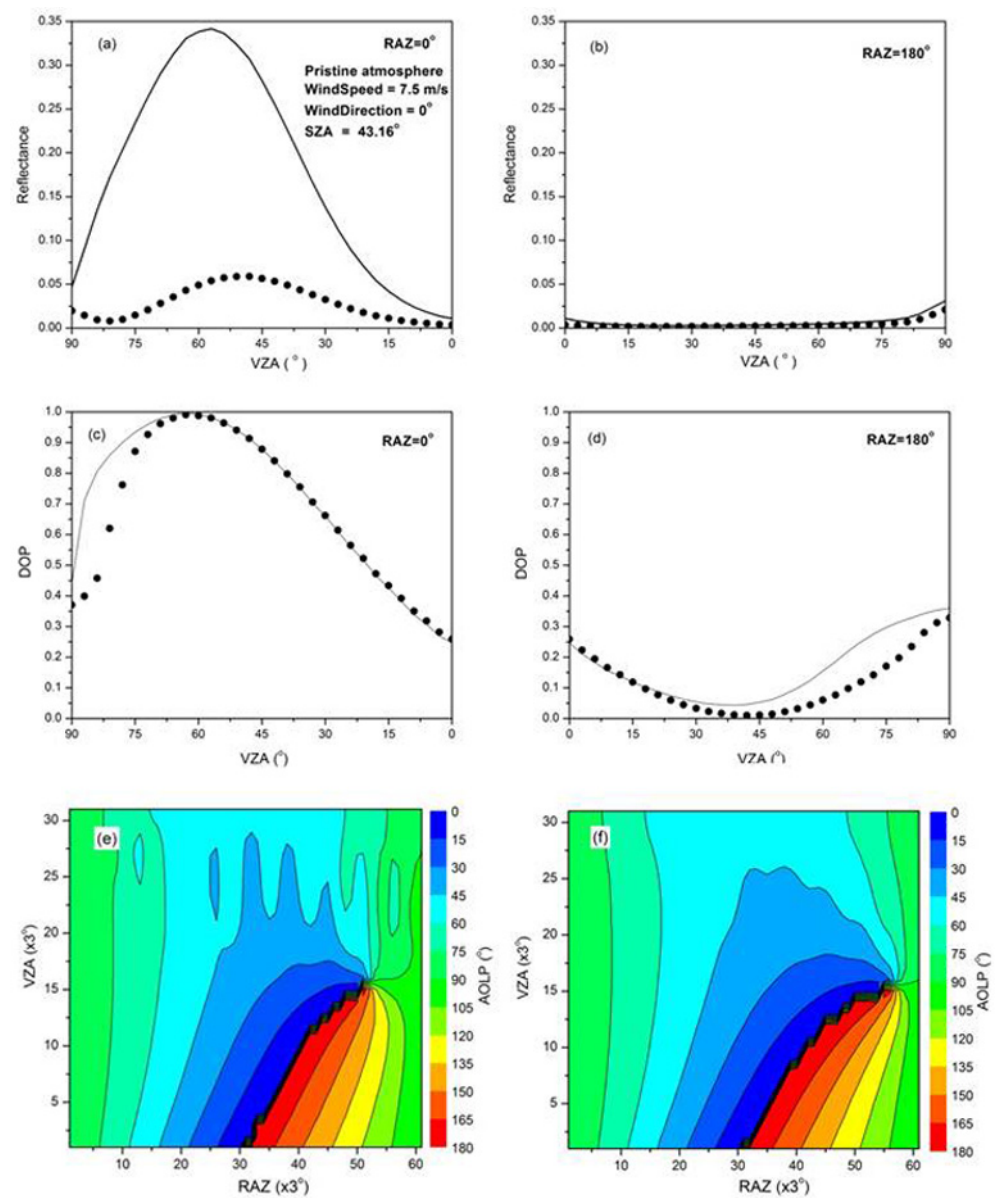

Fig. 7. The total reflectance, DOP, and AOLP at a wavelength of $1200 \mathrm{~nm}$ at TOA, which is calculated with the ADRTM at a solar zenith angle of $43.16^{\circ}$ over a pristine clear-sky ocean with a wind speed of $7.5 \mathrm{~m} \mathrm{~s}^{-1}$ and a wind direction of $0^{\circ}$. Solid curves denote the total reflectance and DOP with the sub-Arctic winter (SAW) atmosphere. Black dots denote the total reflectance and DOP with the tropical (TPC) atmosphere. Panel (e) shows the AOLP with SAW atmosphere and (f) shows the AOLP with TPC atmosphere.

In study of the polarization state of the reflected solar light from the ocean-atmosphere system, there is also a concern that the shadows of ocean waves may affect the DOP and AOLP of the reflected light. In this work, the effect of shadowing by surface waves on reflected light is examined by multiplying the ocean reflection matrix of nonwhitecap part of the ocean by a bidirectional shadowing function (Tsang et al., 1985; Mishchenko and Travis, 1997)

$S\left(\theta_{\mathrm{s}}, \theta_{\mathrm{v}}\right)=\frac{1}{1+\Lambda\left(\theta_{\mathrm{s}}\right)+\Lambda\left(\theta_{\mathrm{v}}\right)}$,

where

$$
\begin{aligned}
\Lambda(\theta) & =\frac{1}{2}\left\{\frac{\sigma}{\cos \theta}\left[\frac{\left(1-\cos ^{2} \theta\right)}{\pi}\right]^{1 / 2} \exp \left[-\frac{\cos ^{2} \theta}{\sigma^{2}\left(1-\cos ^{2} \theta\right)}\right]\right. \\
& \left.-\operatorname{erfc}\left[\frac{\cos \theta}{\sigma \sqrt{1-\cos ^{2} \theta}}\right]\right\},
\end{aligned}
$$

$\sigma$ is calculated with Eq. (20) and $\operatorname{erfc}(x)$ is the complementary error function. Figure 12 shows the total reflectance and
DOP on the principal plane at the wavelength of $670 \mathrm{~nm}$ from the pristine US STD atmosphere over the ocean with and without wave shadows. The wind speed is $7.5 \mathrm{~m} \mathrm{~s}^{-1}$. The SZA is $33.30^{\circ}$. We can see that ocean wave shadowing can significantly reduce the total reflectance at VZA $>\sim 60^{\circ}$, but its effect on reflectance at smaller VZA and on DOP is not big. Shown in Fig. 13 are the AOLPs of the cases in Fig. 12. It can be seen that the ocean wave shadows also do not significantly affect the AOLPs of the reflected solar light. However, ocean wave shadowing effect is considered in all of the following studies and in the future operational PDMs.

To derive PDMs that are adequate for application over broad solar spectral range, we need to investigate the sensitivity of the polarization state of reflected light to the wavelength. Figure 14 shows the total reflectance and DOP of the ocean-atmosphere system on the principal plane, which is calculated with the ADRTM at the wavelengths of 470 and $865 \mathrm{~nm}$, respectively. Pristine US STD atmosphere is used. The SZA is $33.30^{\circ}$. Wind speed is $7.5 \mathrm{~m} \mathrm{~s}^{-1}$. We can see that 

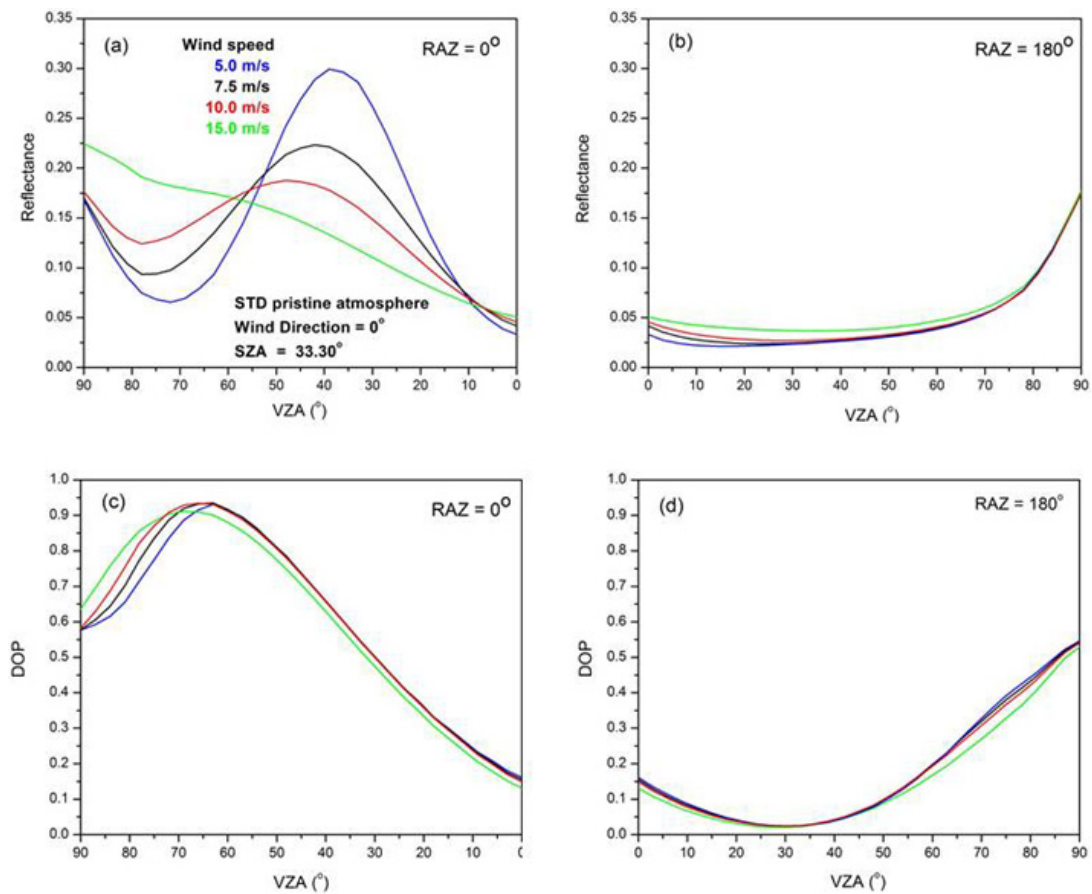

Fig. 8. The total reflectance and DOP of the ocean-atmosphere system on the principal plane, which is calculated with the ADRTM at a wavelength of $670 \mathrm{~nm}$. Pristine US standard (STD) atmosphere is used. The solar zenith angle is $33.30^{\circ}$. Wind direction is at $0^{\circ}$. Wind speeds are $5.0 \mathrm{~m} \mathrm{~s}^{-1}, 7.5 \mathrm{~m} \mathrm{~s}^{-1}, 10.0 \mathrm{~m} \mathrm{~s}^{-1}$, and $15.0 \mathrm{~m} \mathrm{~s}^{-1}$, respectively.
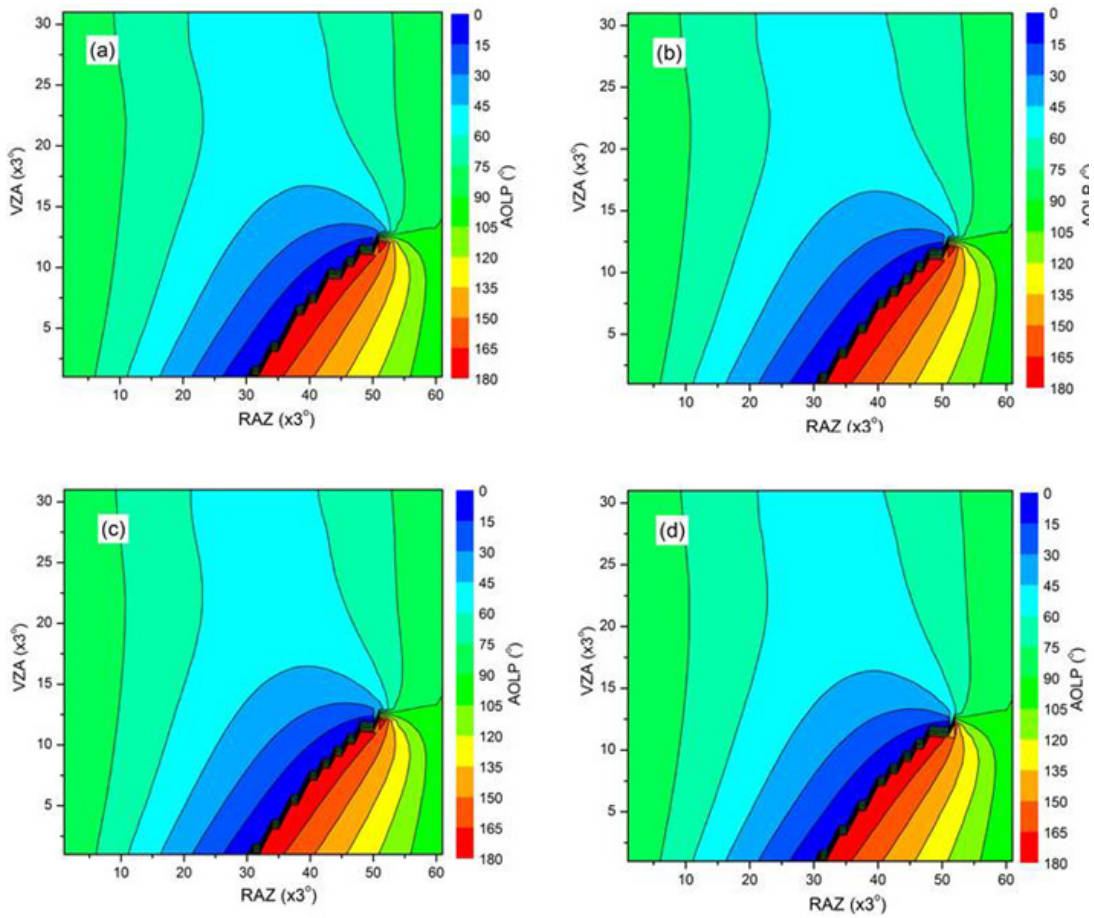

Fig. 9. Same as in Fig. 8, but for AOLP over RAZ of $0-180^{\circ}$ at a wind speed of (a) $5.0 \mathrm{~m} \mathrm{~s}^{-1}$, (b) $7.5 \mathrm{~m} \mathrm{~s}^{-1}$, (c) $10.0 \mathrm{~m} \mathrm{~s}^{-1}$, and (d) $15.0 \mathrm{~m} \mathrm{~s}^{-1}$, respectively. 

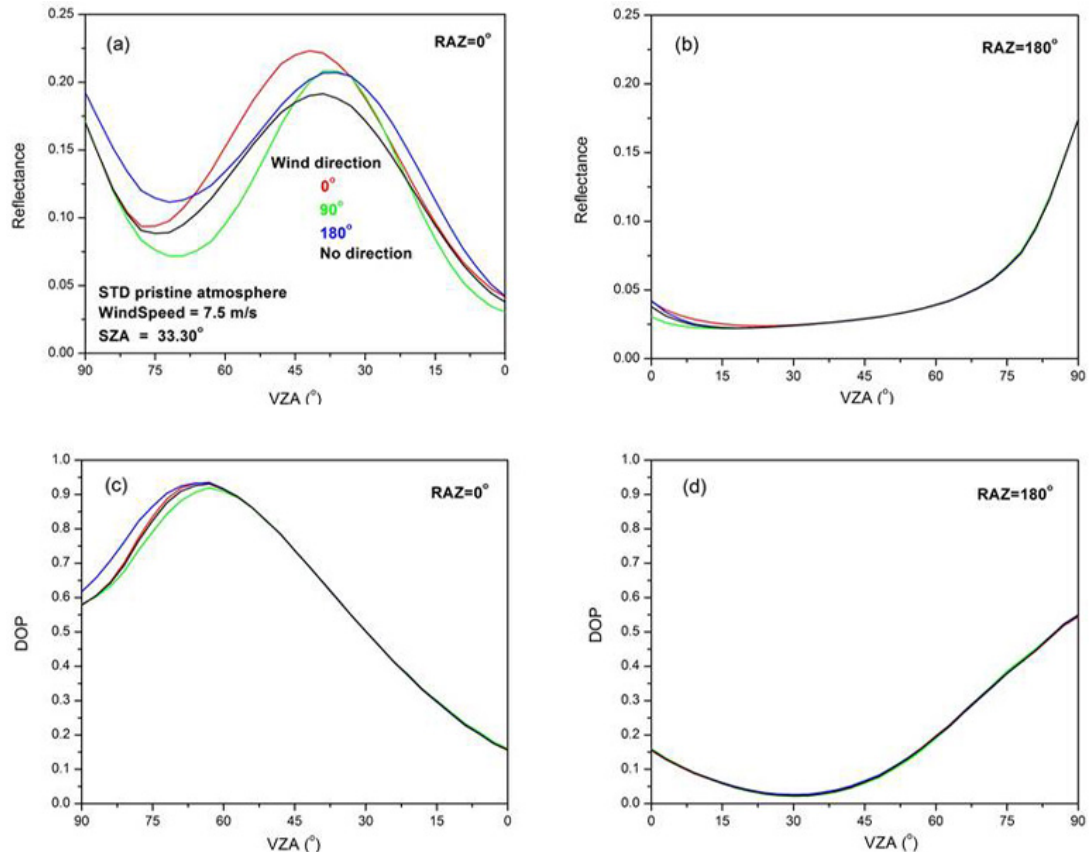

Fig. 10. The total reflectance and DOP of the ocean-atmosphere system on the principal plane, which is calculated with the ADRTM at a wavelength of $670 \mathrm{~nm}$. Pristine US standard (STD) atmosphere is used. The solar zenith angle is $33.30^{\circ}$. Wind speed is $7.5 \mathrm{~m} \mathrm{~s}{ }^{-1}$. Both the ocean wave slope probability distribution model with wind-direction dependence and the one without wind-direction dependence are used in the calculation. In the ocean wave slope probability distribution model with wind-direction dependence, wind direction is set at 0,90 , and $180^{\circ}$, respectively.
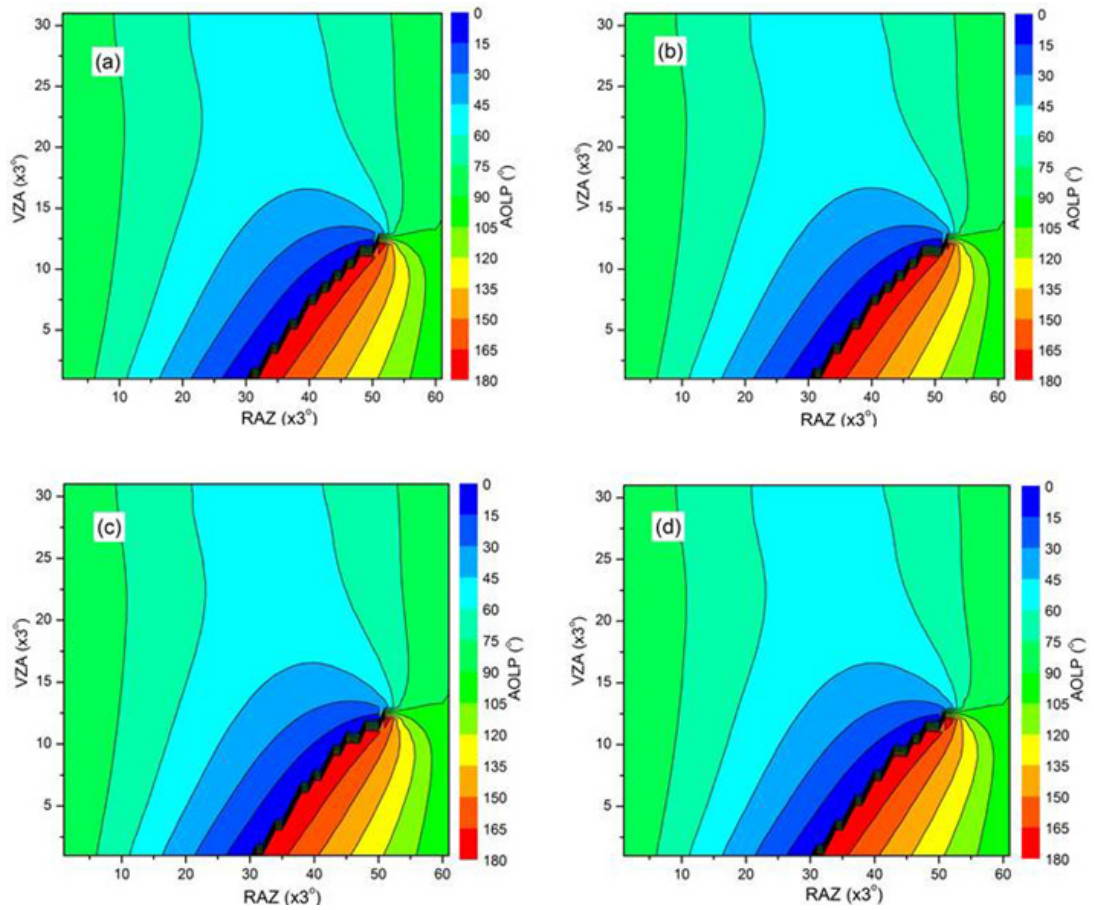

Fig. 11. Same as in Fig. 10, but for the AOLPs from the ocean wave slope probability distribution model with wind direction (a) $0^{\circ}$, (b) $90^{\circ}$, and (c) $180^{\circ}$, and for (d) the ocean wave slope probability distribution model without wind-direction dependence. 

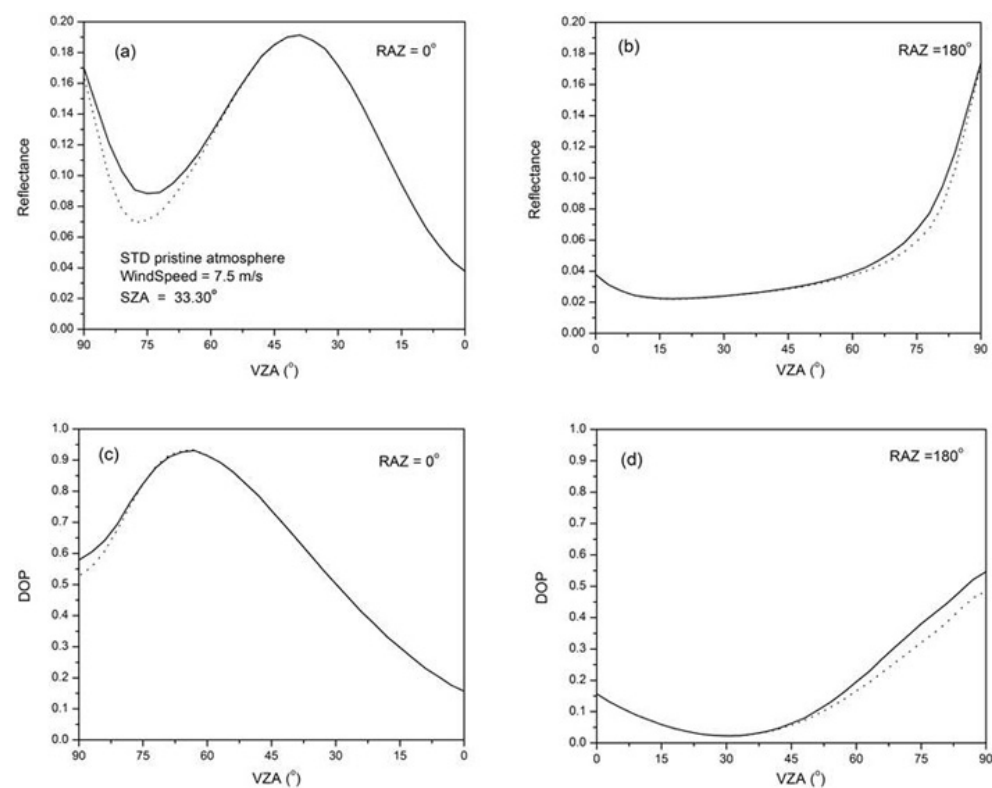

Fig. 12. The total reflectance and DOP of the ocean-atmosphere system on the principal plane, which is calculated with the ADRTM at the wavelength of $670 \mathrm{~nm}$ from the pristine US standard (STD) atmosphere over the ocean without wave shadow (solid curve) and with wave shadow (dashed curve). The wind speed is $7.5 \mathrm{~m} \mathrm{~s}^{-1}$. The SZA is $33.30^{\circ}$.
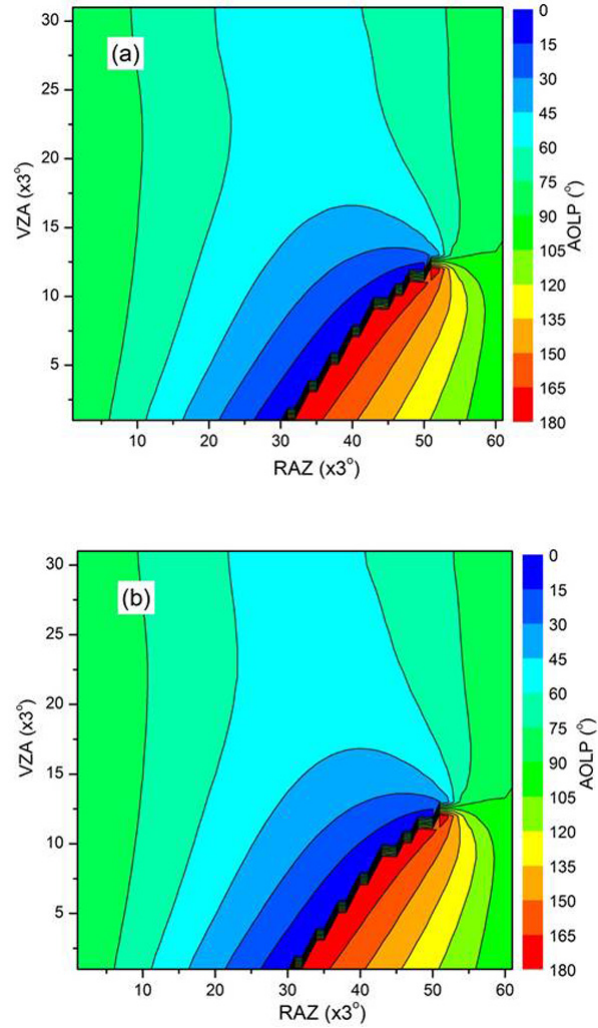

Fig. 13. Same as in Fig. 12, but for AOLPs from the pristine US standard (STD) atmosphere over the ocean (a) without wave shadow and (b) with wave shadow. changing the wavelength can affect the total reflectance very much. Although changing solar wavelength also significantly affects the DOP especially when VZA $>\sim 45^{\circ}$, the DOP's sensitivity to wavelength is not as significant as the total reflectance's. Though not shown here, we also find that increasing the solar zenith angle can largely increase the difference between the DOPs of different wavelengths at all viewing zenith angles. The AOLPs for the cases in Fig. 14 are displayed in Fig. 15. The AOLP's dependence on wavelength is also noticeable. Therefore, the PDMs must be made as a function of solar wavelengths, but may not require very high spectral resolution.

One of the most uncertain components in the atmosphere is aerosols. Effect of aerosols on solar reflectance has been widely studied. Aerosols' effect on polarization of light also attracts many efforts (Chowdhary et al., 2002; Mishchenko et al., 2007, 2013; Sun et al., 2013). In this study, to calculate the effect of aerosols on the polarization state of reflected light at TOA, we chose an example of a US STD atmosphere with sea salt aerosols. The calculation is conducted at the visible wavelength of $550 \mathrm{~nm}$, where the refractive index of sea salt is given as $1.5+i 10^{-8}$ (Chamaillard et al., 2003). The sea salt aerosol particle shapes are assumed to be the agglomerated debris as shown in Fig. 16, and their singlescattering properties are from the DDA calculations (Zubko et al., 2006, 2009, 2013). A two-mode lognormal size distribution (Porter and Clarke, 1997) is applied for the sea salt aerosols in a form 

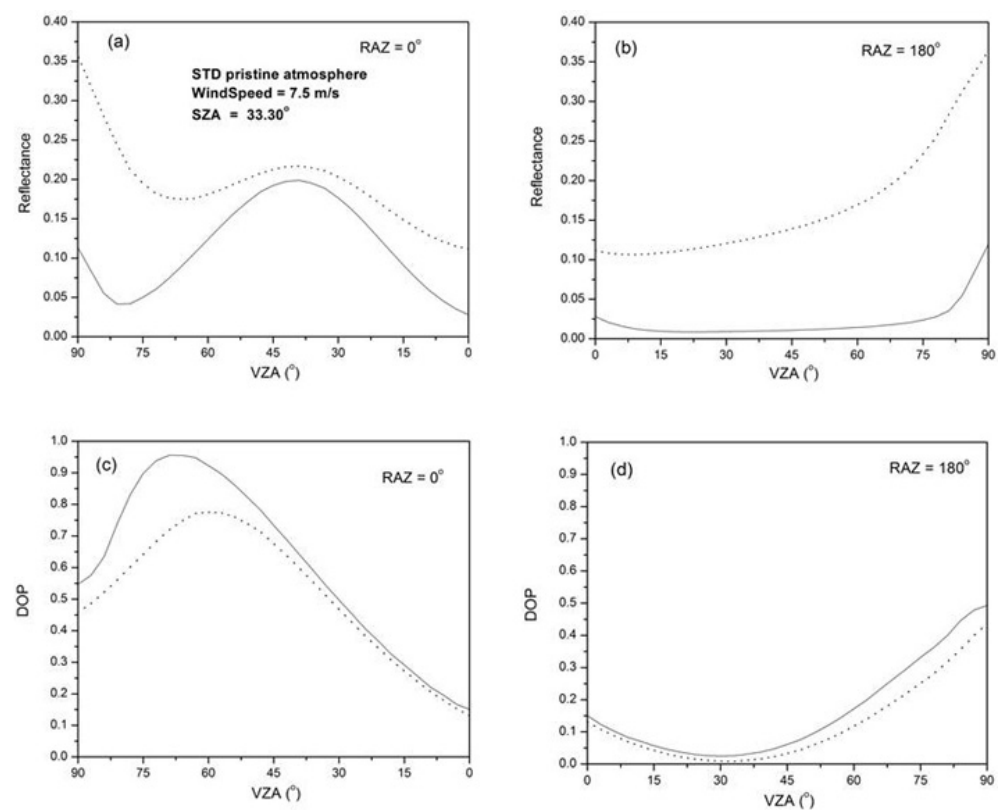

Fig. 14. The total reflectance and DOP of the ocean-atmosphere system on the principal plane, which is calculated with the ADRTM at the wavelengths of $470 \mathrm{~nm}$ (dashed curve) and $865 \mathrm{~nm}$ (solid curve), respectively. Pristine US standard (STD) atmosphere is used. The solar zenith angle is $33.30^{\circ}$. Wind speed is $7.5 \mathrm{~m} \mathrm{~s}^{-1}$.
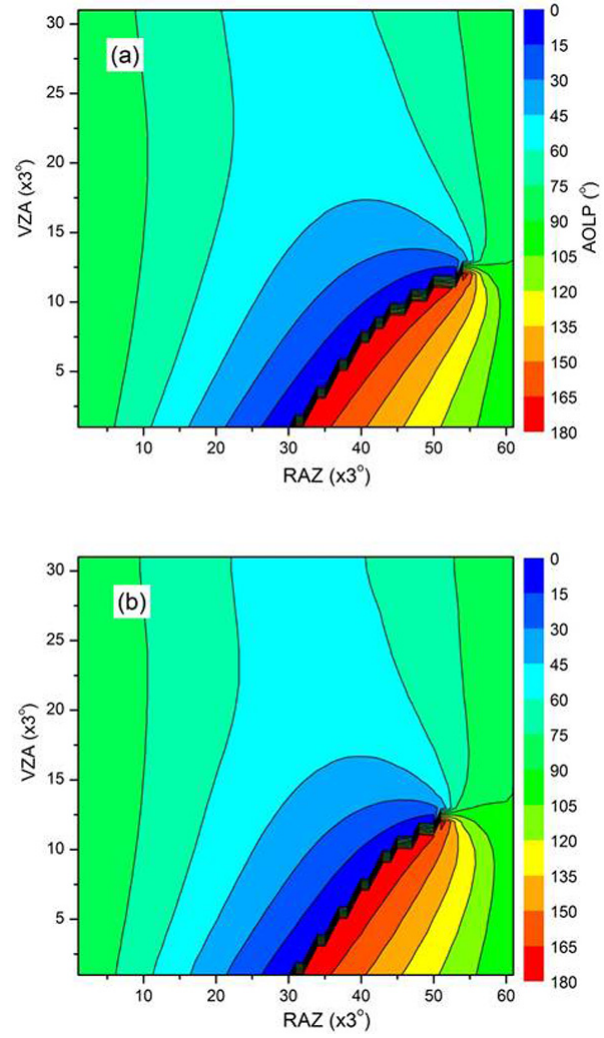

Fig. 15. Same as in Fig. 14, but for AOLPs at the wavelengths of (a) $470 \mathrm{~nm}$ and (b) $865 \mathrm{~nm}$. $\mathrm{d} N / \mathrm{d} \log D=\operatorname{mode}_{1}+\operatorname{mode}_{2}$,

mode $_{i}=\frac{M}{D \log \sigma_{g} \sqrt{2 \pi}} \exp \left[\frac{-\left(\log D-\log D_{g}\right)^{2}}{2 \log ^{2} \sigma_{g}}\right]$ where $i=1,2$.

In Eqs. (26a) and (26b), $D$ is the aerosol diameter in $\mu \mathrm{m}$, $M$ is a multiplier, $\sigma_{g}$ is the geometric standard deviation, and $D_{\mathrm{g}}$ is the geometric mean diameter in $\mu \mathrm{m}$. In this study, we chose a sea salt aerosol case for wind speed between 5.5 and $7.9 \mathrm{~m} \mathrm{~s}^{-1}$ from Porter and Clarke (1997) with all the parameters for fine and coarse mode and size distribution curves shown in Fig. 17. The optical thickness of the aerosol layer is given as 0.1 . Figure 18 shows a comparison of the total reflectance and DOP on the principal plane from the ocean-atmosphere system without aerosols and with sea salt aerosols, respectively. The ocean wind speed is $7.5 \mathrm{~m} \mathrm{~s}^{-1}$. The SZA is $33.30^{\circ}$. We can see that aerosols can increase the total reflectance and decrease the DOP significantly. Although Fig. 19 shows aerosols' insignificant effect on the AOLP, aerosols play an important role in the DOP of the reflected solar light. Thus, in building the PDMs, aerosol effect should be accounted for.

The multiple scattering processes in water clouds can largely depolarize the reflection and thus result in significantly smaller DOP of reflected solar light at TOA than clear-sky ocean. However, the spherical droplets in water clouds have some distinct light scattering features, such as the maxima (rainbow) at scattering angles of $\sim 130-160^{\circ}$ (Deirmendjian, 1964), where the polarization state of scattered light could be very different. A modified gamma (MG) 


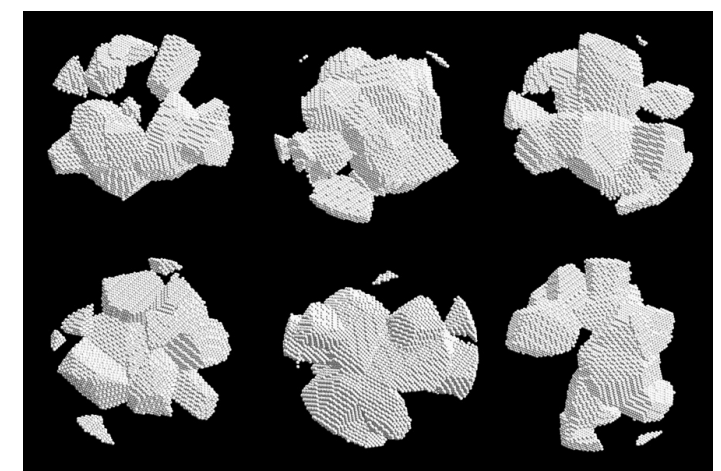

Fig. 16. The agglomerated debris particle shapes of sea salt aerosols.

particle size distribution (PSD) is assumed in this study for water cloud droplets

$\mathrm{d} N / \mathrm{d} R=N_{0} R^{v} \exp \left(-v \frac{R}{R_{0}}\right)$,

where $R$ denotes the droplet radius, $R_{0}$ is the modal radius, $v$ defines the shape of the distribution, and

$N_{0}=\frac{v^{v+1}}{\Gamma(v+1) R_{0}^{\nu+1}} N_{\text {tot }}$

is a constant with $\Gamma(v+1)$ being the gamma function and $N_{\text {tot }}$ being the total number of particles per unit volume (Petty and Huang, 2011). The commonly used C1 size distribution (Deirmendjian, 1969), which is defined by Eq. (27) with $R_{0}=4 \mu \mathrm{m}$ and $v=6$, is applied in this study. Figure 20 shows the total reflectance and DOP on the principal plane, calculated with the ADRTM at the wavelengths of $550 \mathrm{~nm}$, from the ocean-atmosphere system with water clouds of optical thickness 5.0 and 10.0, respectively. The water cloud layer is assumed at $2-3 \mathrm{~km}$ over the ocean. The wind speed is $7.5 \mathrm{~m} \mathrm{~s}^{-1}$. The SZA is $33.30^{\circ}$. The US STD atmosphere is used. It can be seen that the reflectance of the water cloud with optical thickness of 10.0 is nearly two times that of the water cloud with optical thickness of 5.0. However, the reflectance maxima at $\mathrm{VZA}=\sim 2^{\circ}$ and $\mathrm{RAZ}=0^{\circ}$, $\mathrm{VZA}=\sim 35^{\circ}$ and $\mathrm{RAZ}=180^{\circ}$ (rainbow), and $\mathrm{VZA}=\sim 73^{\circ}$ and $\mathrm{RAZ}=180^{\circ}$ exist for both optical thicknesses. Also, at these reflectance maxima angles, the DOP is sensitive to the optical thickness. Larger optical thickness of the water cloud significantly decreases the DOP at these reflectance maxima angles and at other VZAs at RAZ $=0^{\circ}$. However, the DOPs of water clouds are generally relatively small, not larger than $\sim 20 \%$, for most of the viewing angles in this case. Moreover, the AOLPs of these water clouds in Fig. 21 show a very specific angular distribution pattern in the neighborhood of backscattering angles (glory), which is very different from the AOLPs of other scene types. Also, varying optical thickness of water clouds has nearly no effect on the polarization angles.

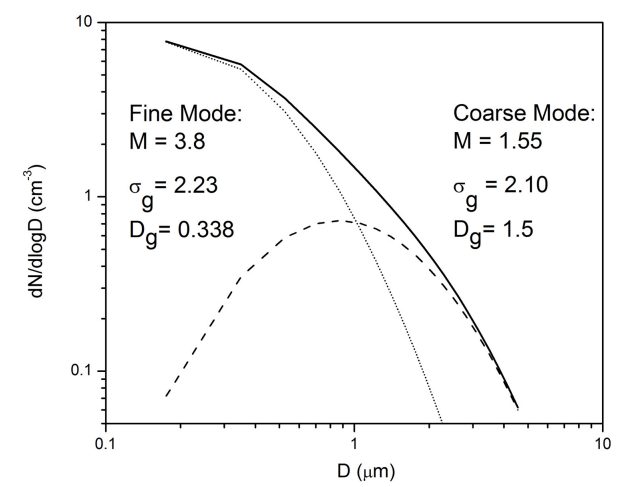

Fig. 17. A two-mode sea salt aerosol size distribution from Porter and Clarke (1997) for ocean wind speed between 5.5 and $7.9 \mathrm{~m} \mathrm{~s}^{-1}$. The dotted curve denotes fine-mode size distribution; the dashed curve denotes coarse-mode size distribution. The combined size distribution is denoted by the solid curve.

To study the polarized reflection from ice clouds, we tested the in-situ-measured 28 ice cloud particle size distributions used in Fu (1996) and various ice cloud particle shapes including solid and hollow columns, plates, smooth and rough surface bullet rosettes of four and six branches, and smooth and rough surface column aggregates. The single-scattering properties of these nonspherical ice crystals are from the geometric ray-tracing approximation (Yang and Liou, 1996). Our tests show that applying different size distributions has a negligible effect on the DOP and AOLP of thin ice clouds. Varying particle shapes can cause as big as $\sim 10 \%$ change in the DOP of thin ice clouds. However, the AOLPs are minimally affected by the particle shapes of ice clouds. Figure 22 gives an example of the size distribution for ice clouds. Also shown in this figure is the assumed ice crystal aggregate particle shape. Figure 23 shows the total reflectance and DOP on the principal plane, which is calculated with the ADRTM at wavelengths $865 \mathrm{~nm}$ from the ocean-atmosphere system composed of an ice cloud layer. The ice cloud layer has an optical thickness 3.0 at wavelength $865 \mathrm{~nm}$. The particle size distribution and the particle shape of the ice cloud are shown in Fig. 22. The ice cloud layer is set between 7 and $8 \mathrm{~km}$ over the ocean with a wind speed of $7.5 \mathrm{~m} \mathrm{~s}^{-1}$. The SZA is $33.30^{\circ}$. The US STD atmosphere is used. We can see that the total reflectance from the thick ice cloud does not have the maxima as shown in Fig. 20 for water clouds. Also, since we assumed randomly oriented ice crystal aggregates in the calculation, there is no specular reflection peak from horizontally oriented ice columns or plates either. The DOPs of the thick ice clouds in Fig. 23 at most of the viewing angles are smaller than $\sim 4 \%$, so the polarization of solar reflection from thick ice clouds may not be an issue for measurements. Due to the insignificant DOP of thick ice clouds, the AOLPs of these clouds are not shown here. However, when ice clouds are so thin that they are transparent to the solar radiation, it becomes a big problem for the polarization state 

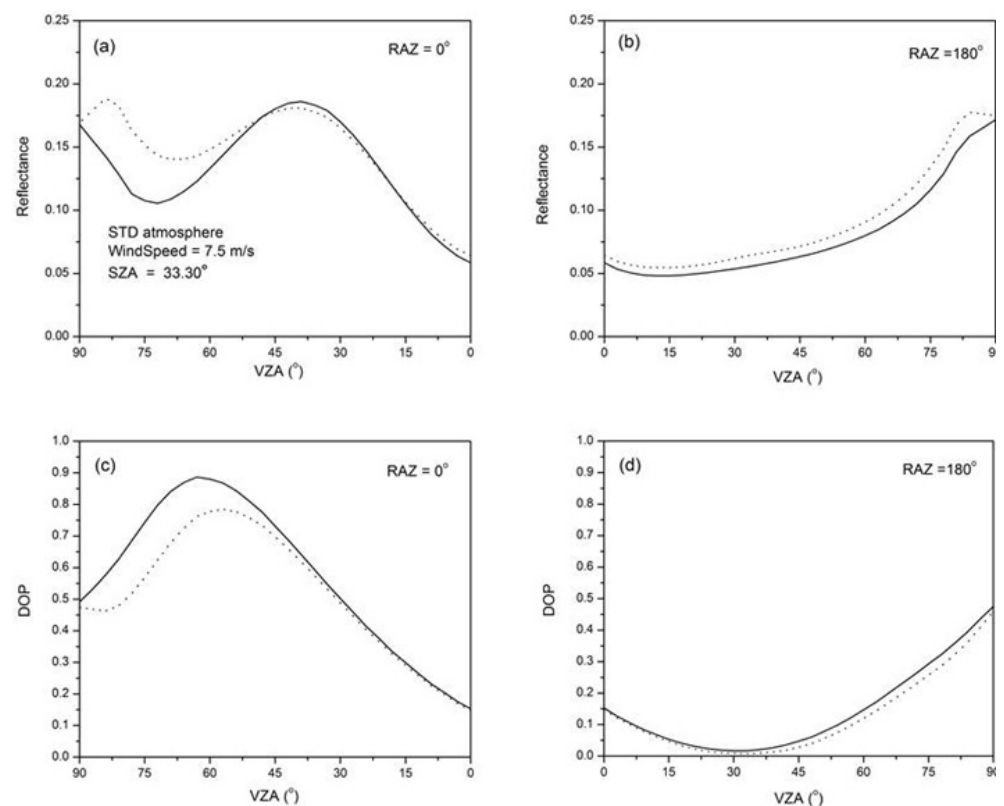

Fig. 18. The total reflectance and DOP on the principal plane, which is calculated with the ADRTM at the wavelengths of $550 \mathrm{~nm}$ from the ocean-atmosphere system without aerosols (solid curve) and with sea salt aerosols (dashed curve) of optical thickness 0.1. The ocean wind speed is $7.5 \mathrm{~m} \mathrm{~s}^{-1}$. The SZA is $33.30^{\circ}$. The US STD atmosphere is used.
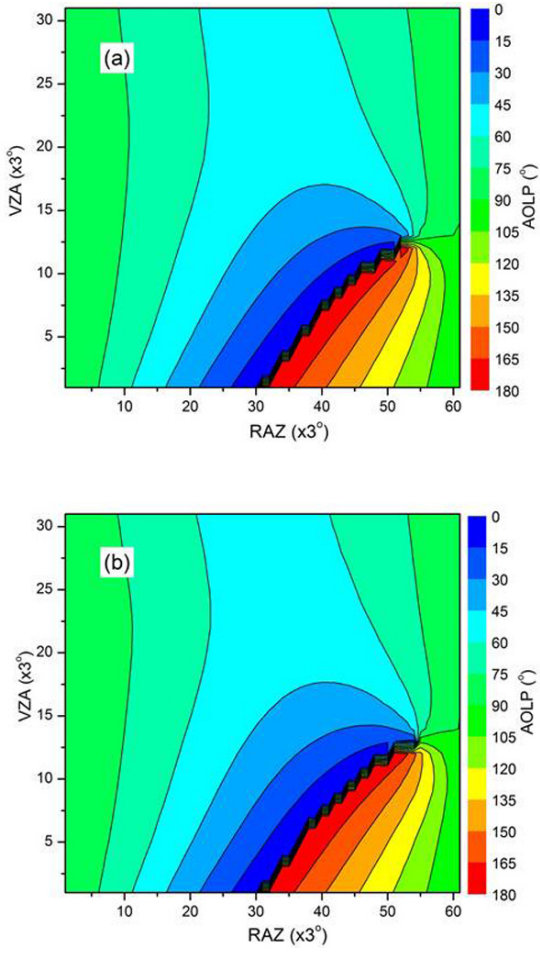

Fig. 19. Same as in Fig. 18, but for the AOLPs of the oceanatmosphere system (a) without aerosols and (b) with sea salt aerosols, respectively. of the reflected light at TOA. Figure 24 shows the same as in Fig. 23, but for an ice cloud optical thickness of 0.3 at $865 \mathrm{~nm}$. Also shown in Fig. 24 is the total reflectance and DOP from the pristine atmosphere for comparison. We can see that the thin cirrus could significantly increase the total reflectance and decrease the DOP of the reflected light from the surface. When VZA is large, as shown in Fig. 25, the AOLPs are also noticeably changed by the thin cirrus. Since thin cirrus clouds are widely distributed around the globe, their effects on the polarization state of reflected solar light from the Earth-atmosphere system must be carefully studied (Sun et al., 2011).

\section{Summary and conclusion}

In this study, the polarized solar radiation reflected from the ocean-atmosphere system is studied with an addingdoubling radiative transfer model (ADRTM). The CoxMunk ocean wave slope distribution model is used in calculation of the reflection matrix of a wind-ruffled ocean surface. An empirical foam spectral reflectance model and an empirical spectral reflectance model for water volume below the surface are integrated in the ocean-surface reflection model. Solar reflectance from the ADRTM is in excellent agreement with that from the discrete-ordinate radiative transfer (DISORT) model at the near-IR wavelength for $\mathrm{VZA}<\sim 80^{\circ}$. The sensitivity studies for the polarized solar radiation are conducted for various ocean-surface and atmospheric conditions for understanding the dependencies 

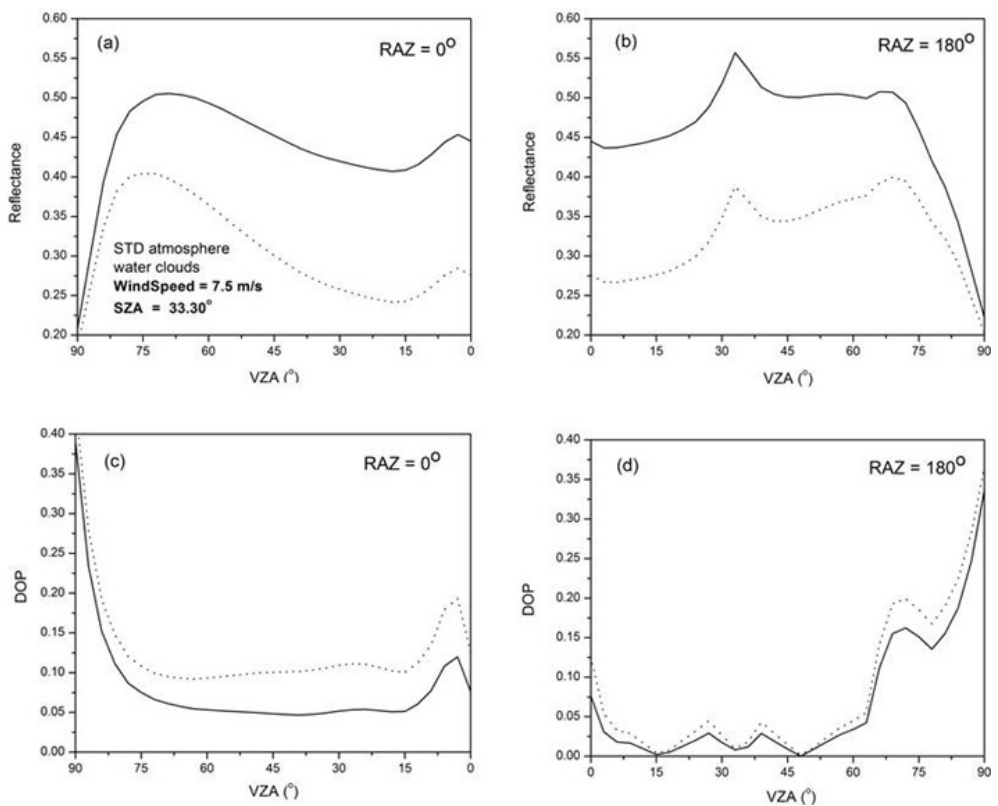

Fig. 20. The total reflectance and DOP on the principal plane, which is calculated with the ADRTM at the wavelength of $550 \mathrm{~nm}$ from the ocean-atmosphere system with water clouds of optical thickness 5.0 (dashed curve) and 10.0 (solid curve), respectively. The ocean wind speed is $7.5 \mathrm{~m} \mathrm{~s}^{-1}$. The SZA is $33.30^{\circ}$. The US STD atmosphere is used.
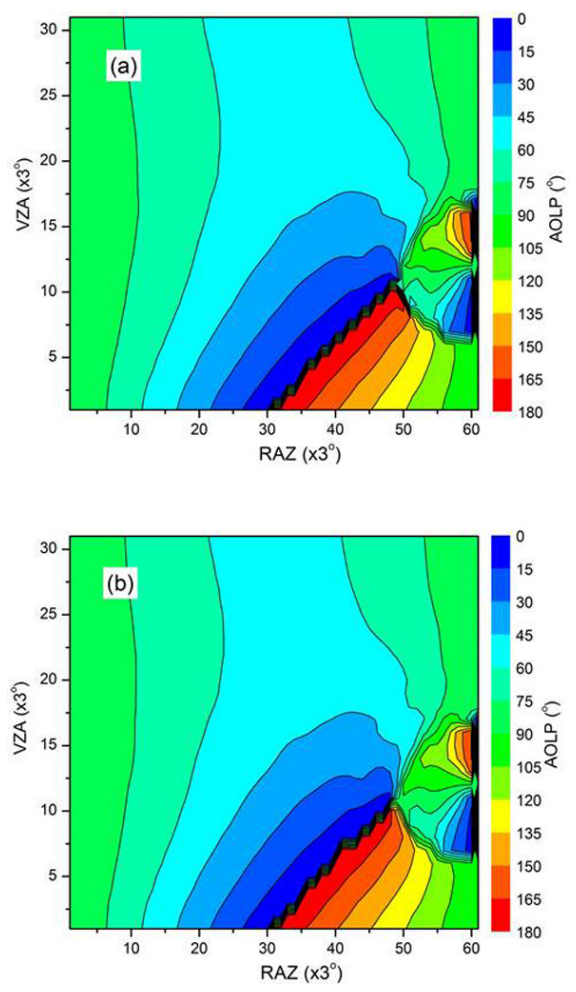

Fig. 21. Same as in Fig. 20, but for the AOLPs of the oceanatmosphere system with water clouds of optical thickness (a) 5.0 and (b) 10.0, respectively.

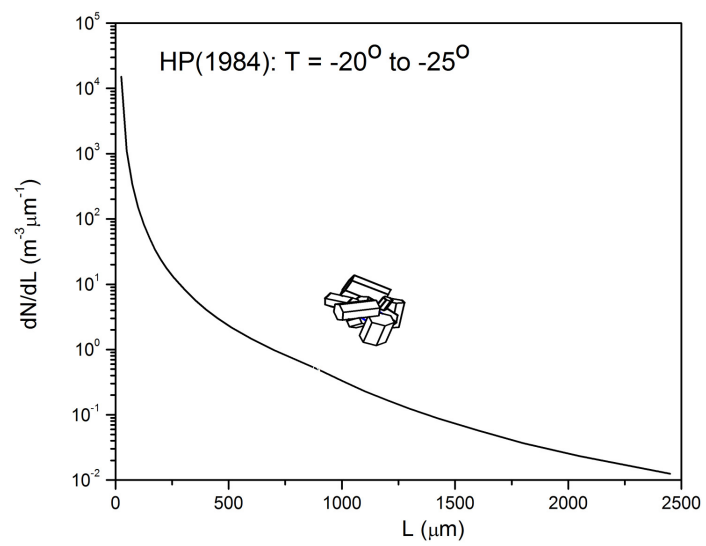

Fig. 22. The ice cloud particle size distribution of HP (1984): $T=-20^{\circ}$ to $-25^{\circ}$ (Fu, 1996). Also shown is the assumed ice crystal aggregate particle shape.

and optimizing the stratification of polarization distribution models (PDMs), which are to be used in the intercalibration of the polarization-sensitive imager measurements with CLARREO data. We found that the total solar reflectance from the ocean-atmosphere system is very sensitive to wavelength, solar and viewing angles, cloud and aerosols, ocean-surface wind speed and direction, and atmospheric gas absorption. However, the degree of polarization (DOP) and angle of linear polarization (AOLP) of the reflected light are less sensitive to ocean wind speed and direction and not very sensitive to atmospheric gas absorption. Water clouds 

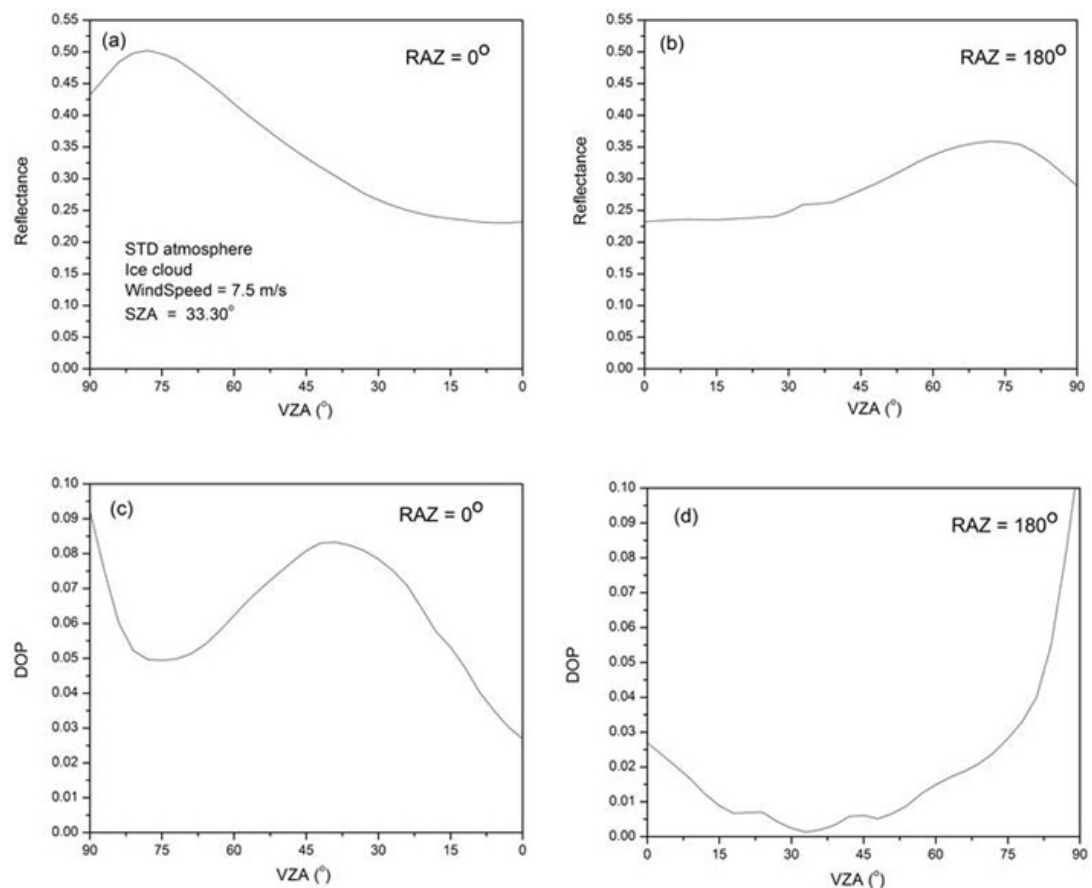

Fig. 23. The total reflectance and DOP on the principal plane, which is calculated with the ADRTM at the wavelength of $865 \mathrm{~nm}$ from the ocean-atmosphere system with an ice cloud layer of optical thickness 3.0 at $865 \mathrm{~nm}$. The ice cloud layer is between $7 \mathrm{~km}$ and $8 \mathrm{~km}$ over the ocean with a wind speed of $7.5 \mathrm{~m} \mathrm{~s}^{-1}$. The SZA is $33.30^{\circ}$. The US STD atmosphere is used.
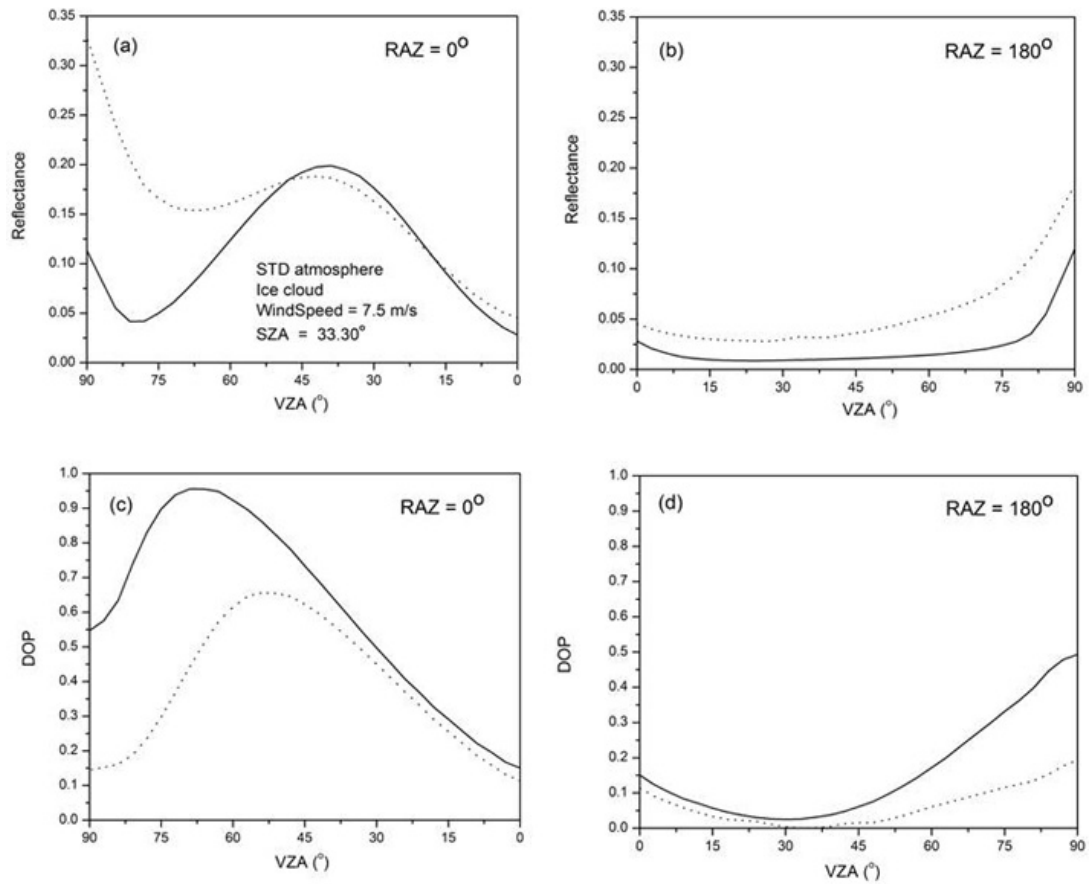

Fig. 24. Same as in Fig. 23, but for an ice cloud layer of optical thickness 0.3 at $865 \mathrm{~nm}$ (dashed curve). Also shown are the total reflectance and DOP from the pristine atmosphere (solid curve) for comparison. 

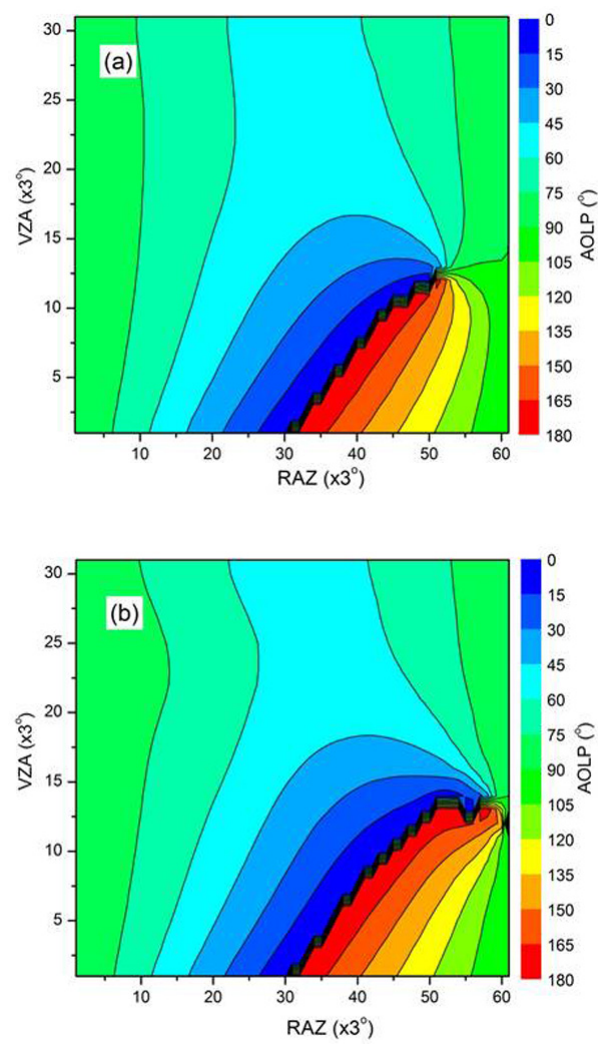

Fig. 25. Same as in Fig. 24, but for the AOLPs of the oceanatmosphere system (a) without ice cloud and (b) with an ice cloud of optical thickness 0.3 at $865 \mathrm{~nm}$, respectively.

generally have small DOPs, but at some specific viewing angles, such as the rainbow angle, their DOPs are still significant. Thick ice clouds have the minimum DOPs, which will not cause significant errors due to polarization in the measurement even by a satellite imager with strong polarization dependence. The major issues related to solar radiation polarization are aerosols and thin ice clouds. The two atmospheric components must be carefully accounted for in making the CLARREO PDMs. The major problem with thin cirrus clouds and aerosols related to the polarization of reflected solar light from the ocean-atmosphere system is their optical thickness. However, although thin cirrus clouds and aerosols could significantly affect DOP, their effect on AOLP is not significant. Also, applying different size distributions has negligible effects on the DOP and AOLP of light from thin ice clouds, and the effect of different particle shapes of thin cirrus on the polarization state of the reflected light is also moderate.

This work demonstrates a radiative transfer methodology for building and optimizing the PDMs as functions of oceansurface conditions, aerosols and clouds, and background atmospheric profiles. Our results provide a reliable approach for calculating the spectral CLARREO PDMs over the broad solar spectra, which cannot be achieved by empirical PDMs based on the analysis of available data from current polarimetric sensors in orbit, although further studies are needed for comparing the modeling results with PARASOL data and for modeling different scene types over land surfaces.

Acknowledgements. This work is supported by NASA's CLARREO mission. The authors thank Bruce A. Wielicki and David F. Young for this support. The authors thank Gorden Videen and Evgenij Zubko for providing the single-scattering properties of feldspar aerosols and Ping Yang for single-scattering properties of ice cloud particles. The authors also thank Bing Lin and Zhonghai Jin for useful discussions and thank Amber L. Richards for proofreading the manuscript. The authors especially thank Rosemary R. Baize for her management help during this work.

Edited by: Q. Fu

\section{References}

Adams, C. N., and Kattawar, G. W.: Solutions of the equations of radiative transfer by an invariant imbedding approach, J. Quant. Spectrosc. Radiat. Trans., 10, 341-356, 1970.

Ambartsumian, V. A.: Theoretical Astrophysics, Pergamon Press, New York, 1958.

Chamaillard, K., Jennings, S. G., Kleefeld, C., Ceburnis, D., and Yoon, Y. J.: Light backscattering and scattering by nonspherical sea-salt aerosols, J. Quant. Spectrosc. Radiat. Trans., 79/80, 577597, 2003.

Chami, M.: Importance of the polarization in the retrieval of oceanic constituents from the remote sensing reflectance, J. Geophys. Res., 112, C05026, doi:10.1029/2006JC003843, 2007.

Chami, M., Santer, R., and Dilligeard, E.: Radiative transfer model for the computation of radiance and polarization in an oceanatmopshere system: polarization properties of suspended matter for remote sensing, Appl. Opt., 40, 2398-2416, 2001.

Chandrasekhar, S.: Radiative Transfer, Oxford University Press, Oxford, 1950.

Chowdhary, J., Cairns, B., and Travis, L. D.: Case studies of aerosol retrievals over the ocean from multiangle, multispectral photopolarimetric remote sensing data, J. Atmos. Sci., 59, 383-397, 2002.

Chowdhary, J., Cairns, B., and Travis, L. D.: Contribution of water leaving radiances to multiangle, multispectral polarimetric observations over the open ocean: Bio-optical model results for case 1 waters, Appl. Opt., 45, 5542-5567, 2006.

Clough, S. A. and Iacono, M. J.: Line-by-line calculations of atmospheric fluxes and cooling rates II: Application to carbon dioxide, ozone, methane, nitrous oxide, and the halocarbons, J. Geophys. Res., 100, 16519-16535, 1995.

Clough, S. A., Iacono, M. J., and Moncet, J.-L.: Line-by-line calculation of atmospheric fluxes and cooling rates: Application to water vapor, J. Geophys. Res., 97, 15761-15785, 1992.

Cornet, C., Labonnote, L. C., and Szczap, F.: Three-dimensional polarized Monte Carlo atmospheric radiative transfer model (3DMCPOL): 3-D effects on polarized visible reflectances of a cirrus cloud, J. Quant. Spectrosc. Radiat. Trans., 111, 174-186, 2010.

Coulson, K. L.: Polarization and Intensity of Light in the Atmosphere, A. Deepak, Hampton, VA, 1988. 
Cox, C. and Munk, W.: Measurement of the roughness of the sea surface from photographs of the sun's glitter, J. Opt. Soc. Amer., 44, 838-850, 1954.

Cox, C. and Munk, W.: Slopes of the sea surface deduced from photographs of sun glitter, Bull. Scripps Inst. Oceanogr., 6, 401-488, 1956.

Dave, J. V.: Meaning of successive iteration of the auxiliary equation of radiative transfer, Astrophys. J., 140, 1292-1303, 1964.

Davies, C.: Size distribution of atmospheric particles, Aerosol Sci., 5, 293-300, 1974.

de Haan, J. F., Bosma, P. B., and Hovenier, J. W.: The adding method for multiple scattering calculations of polarized light, Astron. Astrophys., 183, 371-391, 1987.

Deirmendjian, D.: Scattering and polarization properties of water clouds and hazes in the visible and infrared, Appl. Opt., 3, 187196, 1964.

Deirmendjian, D.: Electromagnetic scattering on spherical polydispersions, American Elsevier Publishing Company, Inc., New York, 1969.

Deschamps, P. Y., Bréon, F. M., Leroy, M., Podaire, A., Bricaud, A., Buriez, J. C., and Sèze, G.: The POLDER mission: Instrument characteristics and scientific objectives, IEEE Trans. Geosci. Remote Sens., 32, 598-615, 1994.

Duan, M., Min, Q., and Lu, D.: A polarized Radiative Transfer model based on successive order of scattering, Adv. Atmos. Sci., 27, 891-900, doi:10.1007/s00376-009-9049-8, 2010.

Evans, K. F. and Stephens, G. L.: A new polarized atmospheric radiative transfer model, J. Quant. Spectrosc. Radiat. Trans., 46, 413-423, 1991.

$\mathrm{Fu}, \mathrm{Q}$.: An accurate parameterization of the solar radiative properties of cirrus clouds for climate models, J. Climate, 9, 20582082, 1996.

$\mathrm{Fu}, \mathrm{Q}$. and Sun, W.: Mie theory for light scattering by a spherical particle in an absorbing medium, Appl. Opt., 40, 1354-1361, 2001.

Hammersley, J. M. and D. C. Handscomb, D. C.: Monte Carlo Methods, Methuen \& Co Ltd., London, 1964.

Hansen, J. E.: Exact and approximation solutions for multiple scattering by cloudy and haze planetary atmospheres, J. Atmos. Sci., 26, 478-487, 1968.

Hansen, J. E. and Hovenier, J. W.: The doubling method applied to multiple scattering of polarized light, J. Quant. Spectrosc. Radiat. Trans., 11, 809-812, 1971.

Hansen, J. E. and Travis, L. D.: Light scattering in planetary atmospheres, Space Sci. Rev., 16, 527-610, doi:10.1007/BF00168069, 1974.

Hovenier, J. W.: Multiple Scattering of Polarized Light in Planetary Atmospheres, Astron. Astrophys., 13, 7-29, 1971.

Irvine, W. M.: Multiple scattering by large particles, Astrophys. J., 142, 1563-1575, 1965.

Kato, S., Ackerman, T. P., Mather, J. H., and Clothiaux, E. E.: The k-distribution method and correlated-k approximation for a shortwave radiative transfer model, J. Quant. Spectrosc. Radiat. Trans., 62, 109-121, doi:10.1016/S0022-4073(98)00075-2, 1999.

Kattawar, G. W. and Adams C. N.: Stokes vector calculations of the submarine light field in an atmosphere-ocean with scattering according to a Rayleigh phase matrix: effect of interface refractive index on the radiance and polarization, Limnol. Oceanogr. 34, 1463-1472, 1989.

Kattawar, G. W., Plass, G. N., and Guinn, J. A.: Monte Carlo calculations of the polarization of radiation in the earth's atmosphereocean system, J. Phys. Oceanogr., 3, 353-372, 1973.

King, M. D., Kaufman, Y. J., Menzel, W. P., and Tanré, D.: Remote sensing of cloud, aerosol and water vapor properties from the Moderate Resolution Imaging Spectrometer (MODIS), IEEE Trans. Geosci. Remote Sens., 30, 2-27, 1992.

Kneizys. F. X., Shettle, E. P., Abreu, L. W., Chetwynd, J. H., Anderson, G. P., Gallery, W. O., Selby, J. E. A., and Clough, S. A.: Users guide to LOWTRAN 7, AFGL-TR-88-0177, 1988.

Koepke, P.: Effective reflectance of oceanic whitecaps, Appl. Opt., 23, 1816-1824, 1984.

Lacis, A. A., Chowdhary, J., Mishchenko, M. I., and Cairns, B.: Modeling errors in diffuse-sky radiation: Vector vs. scalar treatment, Geophys. Res. Lett., 25, 135-138, doi:10.1029/97GL03613, 1998.

Lenoble, J., Herman, M., Deuze, J. L., Lafrance, B., Santer, R., and Tanre, D.: A successive order of scattering code for solving the vector equation of transfer in the earth's atmosphere with aerosols, J. Quant. Spectrosc. Radiat. Trans., 107, 479-507, 2007.

Lukashin, C., Wielicki, B. A., Young, D. F., Thome, K. J., Jin, Z., and Sun, W.: Uncertainty estimates for imager reference intercalibration with CLARREO reflected solar spectrometer, IEEE Transac. Geosci. Remote Sens., 51, 1425-1436, 2013.

Macke, A.: Scattering of light by polyhedral ice crystals, Appl. Opt., 32, 2780-2788, 1993.

Maignan, F., Breon, F.-M., Fedele, E., and Bouvier, M.: Polarized reflectances of natural surfaces: Spaceborne measurements and analytical modeling, Remote Sens. Environ., 113, 2642-2650, 2009.

Mayer, B.: Radiative transfer in the cloudy atmosphere, Eur. Phys. J. Conf., 1, 75-99, 2009.

McClatchey, R. A., Fenn, R. W., Selby, J. E. A., Volz, F. E., and Garing, J. S.: Optical properties of the atmosphere, 3rd Edn., Environ Res. Pap., 411, Air Force Cambridge Res. Lab., Bedford, MA, 1972.

Mie, G.: Beiträge zur optik trüber medien, speziell kolloidaler metallösungen, Leipzig, Ann. Phys., 330, 377-445, 1908.

Min, Q., and Duan, M.: A successive order of scattering model for solving vector radiative transfer in the atmosphere, J. Quant. Spectrosc. Radiat. Trans., 87, 243-259, doi:10.1016/j.jqsrt.2003.12.019, 2004.

Mishchenko, M. I. and Travis, L. D.: Satellite retrieval of aerosol properties over the ocean using polarization as well as intensity of reflected sunlight, J. Geophys. Res., 102, 16989-17013, doi:10.1029/96JD02425, 1997.

Mishchenko, M. I., Cairns, B., Kopp, G., Schueler, C. F., Fafaul, B. A., Hansen, J. E., Hooker, R. J., Itchkawich, T., Maring, H. B., and Travis, L. D.: Accurate monitoring of terrestrial aerosols and total solar irradiance: Introducing the Glory mission, Bull. Amer. Meteorol. Soc., 88, 677-691, 2007.

Mishchenko, M. I., Liu, L. and Mackowski, D. W.: T-matrix modeling of linear depolarization by morphologically complex soot and soot-containing aerosols, J. Quant. Spectrosc. Radiat. Trans., 123, 135-144, 2013. 
Mitchell, D., Chai, S., Liu, Y., Heymsfield, A., and Dong, Y.: Modeling cirrus clouds. Part I: treatment of bimodal size spectra and case study analysis, J. Atmos. Sci., 53, 2952-2966, 1996.

Monahan, E. C. and O'Muircheartaigh, I. G.: Optimal power-law description of oceanic whitecap coverage dependence on wind speed, J. Phys. Oceanogr., 10, 2094-2099, 1980.

Morel, A.: Optical modeling of the upper ocean in relation to its biogenous matter content (Case I waters), J. Geophys. Res., 93, 10749-10768, 1988.

Nadal, F. and Breon, F.-M.: Parameterization of surface polarized reflectance derived from POLDER spaceborne measurements, IEEE Transac. Geosci. Remote Sens., 37, 1709-1718, 1999.

National Oceanic and Atmospheric Administration, National Aeronautics and Space Administration, and United States Air Force: U.S. Standard Atmosphere, NOAA-S/T 76-1562, 1976.

Ota, Y., Higurashi, A., Nakajima, T., and Yokota, T.: Matrix formulations of radiative transfer including the polarization effect in a coupled atmosphere-ocean system, J. Quant. Spectrosc. Radiat. Trans., 111, 878-894, 2010.

Ott, W.: A physical explanation of the lognormality of pollutant concentrations, J. Air Waste Manage. Assoc., 40, 1378-1383, 1990.

Peebles, G. H. and Plesset, M. S.: Transmission of Gamma-rays through large thicknesses of heavy materials, Phys. Rev., 81, 430-439, 1951

Petty, G. W. and Huang, W.: The modified gamma size distribution applied to inhomogeneous and nonspherical particles: Key relationships and conversions, J. Atmos. Sci., 68, 1460-1473, 2011.

Plass, G. N. and Kattawar, G. W.: Monte Carlo calculations of light scattering from clouds, Appl. Opt., 7, 415-419, 1968.

Porter, J. N. and Clarke, A. D.: Aerosol size distribution models based on in situ measurements, J. Geophys. Res., 102, 6035$6045,1997$.

Reist, P. C.: Introduction to Aerosol Science, McMillan, New York, 1984

Rozanov, V. V. and Kokhanovsky, A. A.: The solution of the vector radiative transfer equation using the discrete ordinates technique: selected applications, Atmos. Res., 79, 241-265, 2006.

Schultz, F. M., Stamnes, K., and Weng, F.: VDISORT: An improved and generalized discrete ordinate method for polarized (vector) radiative transfer, J. Quant. Spectrosc. Radiat. Trans., 61, 105122,1999

Stam, D. M., de Haan, J. F., Hovenier, J. W., and Stammes, P.: Degree of linear polarization of light emerging from the cloudless atmosphere in the oxygen A band, J. Geophys. Res., 104, 1684316858, 1999.

Stamnes, K., Tsay, S.-C., Wiscombe, W., and Jayaweera, K.: Numerically stable algorithm for discrete-ordinate-method radiative transfer in multiple scattering and emitting layered media, Appl. Opt., 27, 2502-2509, 1988.

Stokes, G. G.: On the intensity of the light reflected from or transmitted through a pile of plates, Proc. R. Soc. London, 11, 545$556,1862$.

Sun, J. and Xiong, X.: MODIS polarization-sensitivity analysis, IEEE Trans. Geosci. Rem. Sens., 45, 2875-2885, 2007.

Sun, W., Fu, Q., and Chen, Z.: Finite-difference time domain solution of light scattering by dielectric particles with a perfectly matched layer absorbing boundary condition, Appl. Opt., 38, 3141-3151, 1999.
Sun, W., Loeb, N. G., and Fu, Q.: Finite-difference time domain solution of light scattering and absorption by particles in an absorbing medium, Appl. Opt., 41, 5728-5743, 2002.

Sun, W., Videen, G., Kato, S., Lin, B., Lukashin, C., and Hu, Y.: A study of subvisual clouds and their radiation effect with a synergy of CERES, MODIS, CALIPSO and AIRS data, J. Geophy. Res. 116, D22207, doi:10.1029/2011JD016422, 2011.

Sun, W., Liu, Z., Videen, G., Fu, Q., Muinonen, K., Winker, D. M., Lukashin, C., Jin, Z., Lin, B., and Huang, J.: For the depolarization of linearly polarized light by smoke particles, J. Quant. Spectrosc. Radiat. Trans., 122, 233-237, 2013.

Sun, W., Videen, G., Fu, Q., and Hu, Y.: Scattered-field FDTD and PSTD algorithms with CPML absorbing boundary conditions for light scattering by aerosols, J. Quant. Spectrosc. Radiat. Trans., in press, 2013

Tsang, L., Kong, J. A., and Shin, R. T.: Theory of Microwave Remote Sensing, John Wiley, New York, 1985.

Twomey, S., Jacobowitz, N., and Howell, H. B.: Matrix methods for multiple-scattering problems, J. Atmos. Sci., 23, 289-296, 1966.

van de Hulst, H. C.: Scattering in a planetary atmosphere, Astrophys. J., 107, 220-246, 1948.

van de Hulst, H. C.: A new look at multiple scattering, Tech. Rep., Goddard Institute for Space Studies, New York, 1963.

Whitby, K.: The physical characteristics of sulfur aerosols, Atmos. Environ., 12, 135-159, 1978.

Wielicki, B. A., Young, D. F., Mlynczak, M. G., Thome, K. J. Leroy, S., Corliss, J., Anderson, J. G., Ao, C. O., Bantges, R., Best, F., Bowman, K., Brindley, H., Butler, J. J., Collins, W., Doelling, D. R., Dykema, J. A., Feldman, D. R., Fox, N., Holz, R. E., Huang, X., Huang, Y., Jennings, D. E., Jin, Z., Johnson, D. G., Jucks, K., Kato, S., Kirk-Davidoff, D. B., Knuteson, R., Kopp, G., Kratz, D. P., Liu, X., Lukashin, C., Mannucci, A. J., Phojanamongkolkij, N., Pilewskie, P., Ramaswamy, V., Revercomb, H., Rice, J., Roberts, Y., Roithmayr, C. M., Rose, F., Sandford, S. Shirley, E. L., Smith, Sr., W. L., Soden, B., Speth, P. W., Sun, W., Taylor, P. C., Tobin, D., and Xiong, X.: Climate absolute radiance and refractivity observatory (CLARREO): Achieving climate change absolute accuracy in orbit, Bull. Amer. Meteor. Soc., in press, 2013

World Meteorological Organization: Atmospheric ozone 1985, Global ozone research and monitoring project, Report No. 16, 1985

Yang, P. and Liou, K. N.: Geometric-optics-integral-equation method for light scattering by nonspherical ice crystals, Appl. Opt., 35, 6568-6584, 1996.

Zhai, P.-W., Hu, Y., Chowdhary, J., Trepte, C. R., Lucker, P. L., and Josset, D. B.: A vector radiative transfer model for coupled atmosphere and ocean systems with a rough interface, J. Quant. Spectrosc. Radiat. Trans., 111, 1025-1040, doi:10.1016/j.jqstr.2009.12.005, 2010.

Zubko, E., Shkuratov, Y., Kiselev, N. N., and Videen, G.: DDA simulations of light scattering by small irregular particles with various structure, J. Quant. Spectrosc. Radiat. Trans., 101, 416-434, 2006.

Zubko, E., Kimura, H., Shkuratov, Y., Muinonen, K., Yamamoto, T., Okamoto, H., and Videen, G.: Effect of absorption on light scattering by agglomerated debris particles, J. Quant. Spectrosc. Radiat. Trans., 110, 1741-1749, 2009. 
Zubko, E., Muinonen, K., Munoz, O., Nousiainen, T., Shkuratov, Y., Sun, W., Videen, G.: Light scattering by feldspar particles: Comparison of model agglomerate debris particles with laboratory samples, J. Quant. Spectrosc. Radiat. Trans., in press, 2013. 